
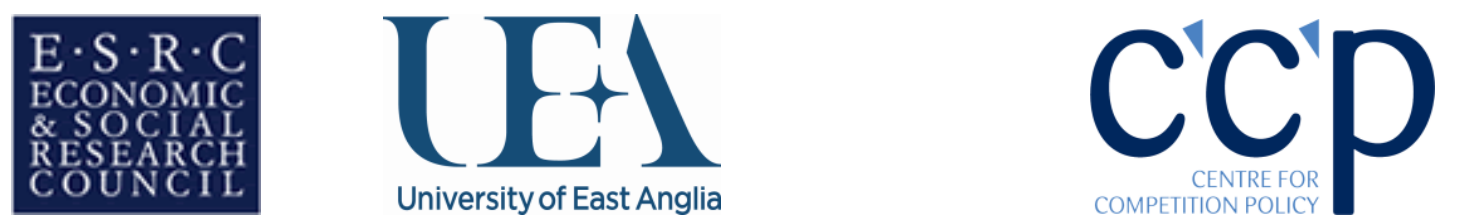

\title{
Market Structure, Regulation and the Speed of Mobile Network Penetration
}

\author{
Yan Li \\ Norwich Business School and Centre for Competition Policy, School of \\ Economics, University of East Anglia, Norwich, NR4 7TJ, U.K. email: \\ li.yan@uea.ac.uk \\ $\&$ \\ Bruce Lyons \\ School of Economics and Centre for Competition Policy, University of East \\ Anglia, Norwich, NR4 7TJ, U.K. email: b.lyons@uea.ac.uk
}

\section{CCP Working Paper 12-3}

\begin{abstract}
The speed of market penetration (i.e. diffusion) is an important summary measure of how well the market works for potential consumers of a new product. This paper identifies the structural features associated with rapid diffusion of mobile telephony. We use a sample of thirty countries over the sixteen years in which average penetration rose from $2 \%$ to $97 \%$ of the population (earlier studies observed only the initial years of diffusion during which there was typically only one or two networks). We find that the history of market structures matters and five firms maximise the speed of consumer uptake. The market structure effect does not appear to work exclusively through the level of prices. Digital technology, standardisation, privatization and independent regulation are also important positive factors, and we identify the speed and dimensions of catch-up.
\end{abstract}

31st October 2011

JEL Classification Codes: L13, L51, L96

Keywords: competition; market structure; privatization; independent regulator; mobile network; diffusion 
Acknowledgements: We thank Stephen Davies, Jon Stern, Paul Stoneman and Catherine Waddams for comments and discussions. We also thank two referees and the editor for very helpful suggestions. Earlier versions of this paper were presented at the conferences of EARIE, the Competition Law and Economics European Network (CLEEN) New Researchers Workshop, and CRESSE 2010. Financial support of the Economic and Social Research Council is gratefully acknowledged.

\section{Contacts Details:}

Bruce Lyons, Corresponding author: School of Economics and Centre for Competition Policy, University of East Anglia, Norwich, NR4 7TJ, U.K. email: b.lyons@uea.ac.uk

Tel: +44 1603 592084/591623 Fax: +44 1603591622 


\title{
MARKET STRUCTURE, REGULATION AND THE SPEED OF MOBILE NETWORK PENETRATION*
}

\author{
by \\ YAN LI \\ BRUCE LYONS ${ }^{\dagger \dagger}$
}

\begin{abstract}
${ }^{\dagger}$ Norwich Business School and Centre for Competition Policy, School of Economics, University of East Anglia, Norwich, NR4 7TJ, U.K. email: li.yan@uea.ac.uk

$\dagger$ [Corresponding author] School of Economics and Centre for Competition Policy, University of East Anglia, Norwich, NR4 7TJ, U.K. email: b.lyons@uea.ac.uk

Tel: +441603 592084/591623 Fax: +441603591622
\end{abstract}

Version date: 31 st October 2011

\begin{abstract}
The speed of market penetration (i.e. diffusion) is an important summary measure of how well the market works for potential consumers of a new product. This paper identifies the structural features associated with rapid diffusion of mobile telephony. We use a sample of thirty countries over the sixteen years in which average penetration rose from $2 \%$ to $97 \%$ of the population (earlier studies observed only the initial years of diffusion during which there was typically only one or two networks). We find that the history of market structures matters and five firms maximise the speed of consumer uptake. The market structure effect does not appear to work exclusively through the level of prices. Digital technology, standardisation, privatization and independent regulation are also important positive factors, and we identify the speed and dimensions of catch-up.
\end{abstract}

JEL Classification Codes: L13, L51, L96

Keywords: competition; market structure; privatization; independent regulator; mobile network; diffusion

* We thank Stephen Davies, Jon Stern, Paul Stoneman and Catherine Waddams for comments and discussions. We also thank two referees and the editor for very helpful suggestions. Earlier versions of this paper were presented at the conferences of EARIE, the Competition Law and Economics European Network (CLEEN) New Researchers Workshop, and CRESSE 2010. Financial support of the Economic and Social Research Council is gratefully acknowledged. 


\section{Introduction}

In the context of a growing market with consumer network externalities, the speed of a new product's market penetration (i.e. diffusion) is an important summary measure of how well the market is performing for potential consumers. Delays in uptake can result in large welfare losses. ${ }^{1}$ When the market is regulated, it is particularly important to understand how the various potential regulatory levers (e.g. number of firms, public ownership, price controls) affect the diffusion process. As penetration approaches saturation, usage becomes the more important indicator of market performance, but new consumer products continue to be developed and their speed of diffusion is of considerable significance. In this paper we focus on understanding the central period of diffusion in which average market penetration across the more developed economies rose from less than $2 \%$ to nearly $97 \%$ over 16 years.

Like any other product, the demand for mobile phone services is influenced by a range of marketing and technical factors that constitute the overall product 'offer'. This offer includes price level, price structure (e.g. cost of sending relative to receiving a call), reach (geographic coverage) and reliability. Individual elements of the product offer are difficult to observe and measure on a consistent basis either internationally or over time. Furthermore, the optimal balance in the offer can be sensitive to national idiosyncrasies. In fact, one of the theoretical virtues of a competitive market is that it creates incentives for firms to respond to these idiosyncrasies and to provide the most attractive offer to consumers. This leads us to focus on the structural characteristics of the market that drive competition. The aim of this paper is to identify those structural features that are associated with the competitive environment which maximises the rate of diffusion of mobile telephony through the population.

Mobile network penetration has been expanding rapidly in recent years, though there are signs it is reaching maturity in the advanced countries. We employ a panel of 29 OECD countries and China over the period 1991-2006. We include China because of its scale and economic growth at the time, but we also test for robustness using the OECD-only sample. ${ }^{2}$ This period covers the core of the penetration phase in each market. ${ }^{3}$

\footnotetext{
${ }^{1}$ See Hausman (1997).

${ }^{2}$ The Chinese mobile network market has grown fast but it is not immediately clear whether this is a distinct phenomenon or if it is following a similar pattern to OECD countries conditional on its market structure. As the market with the highest number of mobile phone subscribers and the largest market potential, China also provides a robustness check on our core relationship between structure and diffusion.

${ }^{3}$ In contrast, fixed-line markets have stagnated with a national average fixed-line penetration in our sample growing slowly to just under $51 \%$ in 2000 then shrinking (see Table 1 below).
} 
We focus on three structural features: the number of firms; ownership (i.e. privatization); and the existence of an independent industry regulator. Although the number of mobile networks is tightly regulated, we also investigate the potential endogeneity of market structure. Earlier work on telecom market penetration (including fixed line) focused on demographic and technology factors, privatization, first new entry and the early part of the diffusion process. ${ }^{4}$ The latter two limitations appear to be important because, by using data that more completely covers the core diffusion years for the countries in our sample and distinguishing between different numbers of firms, we find substantial effects beyond the simple monopoly versus duopoly dichotomy. ${ }^{5}$ Thus, while previous work has typically found that opening the market beyond monopoly is beneficial, it provides little guidance for important competition policy issues such as the number of operators to be licensed or merger regulation. The previous empirical literature also has little to say about regulatory institutions. Our main contributions are to distinguish the fine-grained effects of each extra entrant and other factors, and to estimate our model over the core years of the diffusion process. ${ }^{6}$ Having identified the key structural features associated with rapid diffusion, we go on to ask whether the effect of a more competitive structure works mainly through the average price level as distinct from non-price-level elements in the offer.

The remainder of this paper is structured as follows. In the next section, we review some related literature on competition, ownership and regulation in telecoms markets. Section 3 sets out the econometric methodology and Section 4 describes the data. Section 5 presents and discusses the empirical results, including tests for endogenous market structure. Section 6 concludes.

\footnotetext{
${ }^{4}$ For work on fixed line penetration, see for example: Ros (1999, 2003); Wallsten (2001, 2004); Fink et al. (2001); McNary (2001); Li and Xu (2002, 2004); Gasmi et al. (2006). The effect of competition has been tested using either a binary dummy variable (e.g., Ros, 1999, 2003; Fink et al., 2001) or indirect proxies of competition from other telecom segments (e.g., Li and Xu, 2002, 2004; Wallsten, 2001, 2004). Work on mobile penetration has investigated the early stages of diffusion and focused on technological constraints, technology 'generations', industry standards, and entry regulation (e.g. Gruber and Verboven, 2001a and 2001b, whose data covers the period 1984-97). Our work is most closely related to the latter. See also Liikanen et al (2004) for technological generation effects, Koski and Kretschmer (2005) for 2G diffusion 1991-99, and Grajek and Kretschmer (2009) for usage intensity in $2 \mathrm{G}$.

${ }^{5}$ The number of mobile networks is regulated and limited for reasons including spectrum scarcity. We later investigate possible endogeneity.

${ }^{6}$ There appears to be little econometric research on the relationship between industrial organization and the uptake of consumer goods in other markets.
} 


\section{Entry, ownership and regulation in mobile telecommunications}

We identify three structural dimensions to telecommunications competition: the number of networks; private (versus state) ownership; and the existence and independence of an industry regulator.

A number of studies of mainly fixed line telecom markets have found that 'competition' is associated with higher penetration, productive efficiency, lower service price and better service quality. Neither the fixed line studies nor early mobile studies were able to address questions relating to the extent of oligopolistic competition. There was very little experience of other than monopoly and duopoly market structures and, importantly, only the early part of the mobile diffusion process was observable in the data. Market structure in fixed line studies has mainly been measured by either a binary competition variable ${ }^{7}$ or indirect proxies from other telecom segments. ${ }^{8}$ For mobile diffusion, Gruber and Verboven (2001a, 2001b) include a duopoly dummy variable which they find to be statistically significant but quantitatively small. Liikanen et al. (2004) include two market structure variables: the number of firms and a 3-firm Herfindahl index. Both are entered linearly and neither is statistically significant. The most recent observation in these papers is 1998 which, as shown in the next section, is still early in the diffusion process. ${ }^{9}$

Our dataset includes a richer range of market structures from monopoly up to seven networks, and our empirical model allows for a very flexible relationship between the number of networks and diffusion. Given specific network effects and high investment costs, it is not clear that this relationship should be monotonic. For example, switching costs between operators, including pecuniary externalities that can be created by the price structure in mobile telephony (e.g. on-net calls may be charged at a discount to off-net), there are incentives to compete for the market, even when there are relatively few competitors. On the other hand, it is possible that if there are 'too many' operators who are unlikely to leave the market, the achievable market share may be small and they may each have a reduced incentive to invest in activities that would attract new consumers into the market. ${ }^{10}$ Consequently, we allow for possible non-monotonicity in the relationship between consumer uptake and the number of firms.

\footnotetext{
${ }^{7}$ E.g. Ros (1999, 2003); Fink et al (2001). Boylaud and Nicoletti (2000) do measure competition by a continuous variable: the market share of new entrants.

${ }^{8}$ See, e.g. Li and Xu (2002, 2004); Wallsten (2001, 2004).

${ }^{9}$ Considering 2G diffusion, Koski and Kretschmer (2005) construct a dummy variable only for three or more competitors, which they find significant.

${ }^{10}$ For example, Sutton (1991, pp.48-54) develops a symmetric Cournot model with endogenous investment in quality. If the number of firms is fixed, his equation (1) shows that investment in perceived quality increases in the
} 
Mobile network licensing is tightly regulated. Nevertheless, it is important to take consider of the possible endogeneity of market structure. In particular, as the market grows in markets with free entry, we normally expect more firms to enter, though less than proportionately if entry reduces price. This is the most robust relationship in the economics of (unregulated) market structure, though exceptions can arise if there are important endogenous sunk costs (Sutton, 1997 and 2000). These exceptions occur only where the main focus of competition is through vertical product differentiation which can be enhanced by overhead investments. In such cases, a similarly concentrated market structure may be observed across different countries/markets and over time. However, the main form of competition between mobile networks is in price structures and not in escalating investments. ${ }^{11}$ Therefore, if there were free entry, this would lead to a positive relationship between the number of mobile networks and market size. We test for this in section 5.1 .

In practice, there is not free entry into mobile network markets. Entry is tightly controlled by licensing, and the number of licences is chosen by the government or a regulator. ${ }^{12}$ Spectrum width provides a technological constraint on the number of licences. Garrard (1997) provides detailed country studies of market evolution up to 1997 in each of the countries in our sample. The evidence is that entry is determined by technology and politics, and not by the standard economics of free entry. Nearly all countries require licences to operate telecom services, in addition to appropriate spectrum allocation. ${ }^{13}$ Once the number of licences has been determined, they are allocated administratively or by some form of contest. There is usually no shortage of potential entrants. For example, even as early as 1989 all seven US regional Bell companies,

number of firms up to $\mathrm{N}=3$, but decreases in $\mathrm{N}$ for $\mathrm{N}>3$. This is a simple model of a non-network industry and the precise result is sensitive to functional form. However, it illustrates how investment incentives need not be monotonic in market structure.

\footnotetext{
${ }^{11}$ For example, substantial geographic coverage is normally established before a new network becomes operational. The extra cost of each new technology generation has been high and brought higher quality and better services. However, this generational technology has often been to a common standard. Even when not a common standard, it has not been an escalating investment by individual network operators to gain a decisive advantage over rival networks.

${ }^{12}$ See, for example, Gruber and Verboven (2001a or 2001b). Mergers are also regulated though they may be more likely to be approved if the market is perceived as sufficiently competitive. Mergers were not a substantial issue in the period and countries in our sample.

${ }^{13}$ The only European exception was Sweden, where theoretically anyone could set up a network. "In practice, however, Televerket was able to create a de facto monopoly... since it had complete control of all the regulatory aspects that must be addressed if competition is to be effective, including spectrum allocation and interconnection" (Garrard, 1997, p.265). Consequently, a licensing regime in the hands of an independent regulator was created in 1992.
} 
five other US cellular operators, four from the UK, three from France and several others joined the contest for the second German licence to be awarded. ${ }^{14}$

The timing of entry depends on political context and technological opportunities, most notably the advent of digital. Digital technology encouraged regulators to issue more licences as more spectrum was released. Digital also improved privacy, opened up new services, most notably SMS messaging that became attractive to low budget consumers, and encouraged improved handset design. In Europe, the European Commission was influential both in supporting a single digital standard, GSM, and in requiring each member state to license at least two rival networks (even in Luxembourg with its population of only half a million) and protecting entrants from anticompetitive practices by incumbents. In the USA, the FCC determined a complex set of licence auctions 1994-96 which resulted in a step increase in the number of networks operating in each region. Canada and, with a delay, Mexico followed a similar pattern to the USA. Political idiosyncrasies moulded market structure across the world. For example, Japan had the world's first mobile network in 1979, but it was very high priced and with low uptake. A second operator was initially licensed to service west Japan in 1989 but soon formed a national service though with incompatible standards. Two more licences were released in 1992. In contrast, China, New Zealand and Norway have continued with duopolies first established in the 1990s. Exit and consolidation within markets was rare during our period. Overall, there is a strong a priori case for market structure being exogenous in relation to the diffusion equation.

The received evidence on ownership is that the success or failure of privatization is highly dependent on political and economic environments in general and the post-privatization regulatory framework in particular. ${ }^{15}$ A survey by Megginson and Netter (2001) suggests that, on balance, deregulation and liberalization in the wider telecom sector are associated with significant improvements in performance and efficiency, but the impact of privatization alone is less clear. This general finding is supported by fixed-line telecom studies that have tried to identify the characteristics of regulatory institutions which determine the quality of regulatory governance. ${ }^{16}$ They find consistently that the existence of a strong and independent regulator is

\footnotetext{
${ }^{14}$ In fact, they joined with local German partners to form ten competing consortia. The winning group led by Mannesmann built the network which eventually launched in June 1992. A third licence was awarded in 1992 particularly aimed at improving services in the recently reunified East.

${ }^{15}$ See Levy and Spiller (1994, 1996); Ramamurti (2000); Villalonga (2000); Yarrow (1986); North (1990).

${ }^{16}$ See, for example, Stern and Holder (1999); Gutierrez and Berg (2000); Gual and Trillas (2003); Gutierrez (2003a, 2003b); Cubbin and Stern (2006); Gasmi et al. (2006); Parker and Kirkpatrick (2005). Exceptionally, Maiorano and Stern (2007) use data from low and middle-income countries over a 15-year period of 1990-2004 to
} 
a key institutional element that tends to be associated with higher levels of performance measures (including fixed-line penetration). Beyond the general regulatory functions (e.g. preventing anticompetitive behaviour), the existence of an independent regulator signals the credibility of a government's commitment to private investments and the government's propensity to undertake effective pro-competition policies. ${ }^{17}$ Following the literature, we define an 'independent regulator' as one which is separated from industrial operators and other governmental bodies, backed by legislation rather than executive decree and able to make decisions independently. The regulatory relationship may be different if firms are publicly owned because there is more likely to be a legislative or heavy lobbying response to regulatory decisions that are seen to harm public enterprises.

\section{Econometric specification}

Mobile network penetration is encouraged by consumer adoption externalities and constrained by market saturation. The balance of these two effects means that it follows a classic S-shaped epidemic growth curve. Figure 2 illustrates this using our data for thirty countries. We therefore adopt the standard logistic specification for our empirical model. ${ }^{18}$ This implies that, for example, an increase in competition will have a greater percentage point impact on penetration when around half the population has adopted a mobile network, as compared with when the product is either new and trying to gain traction in the market, or mature and nearing market saturation.

\section{Fig. 2 near here}

More specifically, let $M_{o b P e n}$ denote the number of people per 100 inhabitants that have adopted a mobile network service in country $i$ at time $t$. Let $M_{i}^{*}$ denote the full saturation level of mobile network adoption (also as a percentage of the population). If the growth rate of penetration is proportional to the proportion of the market that is as yet unserved, with the factor of proportion being $b_{i t}$, we have:

MobPen $_{i t}=\frac{M_{i}^{*}}{1+\exp \left(-\left(a_{i t}+b_{i t} t\right)\right)}$

investigate the relationship between regulatory institutions and performance in the mobile telecommunications sector. However, their results are mixed and do not take account of market structure.

${ }^{17}$ See Armstrong and Sappington (2006); Ramamurti (2000); Villalonga (2000); Levy and Spiller (1994, 1996).

${ }^{18}$ See Griliches (1957) and Mansfield (1961) for early analysis of the logistic growth curve, and Geroski (2000) for an evaluation of its merits. 
We refer to $b_{i t}$ as the speed of diffusion. $a_{i t}$ shifts the diffusion curve forwards or backwards in time without changing its basic shape and is sometimes known as the location parameter. Rearrangement of (1) provides the following model for estimation:

$$
y_{i t}=\ln \left(\frac{\text { MobPen }_{i t}}{M_{i}^{*}-\text { MobPen }_{i t}}\right)=a_{i t}+b_{i t} t+u_{i}+\varepsilon_{i t}
$$

where $u_{i}$ is a country specific error (i.e. time invariant unobserved heterogeneity for each country $i) ;{ }^{19}$ and $\varepsilon_{i t}$ is a standard white noise error term. Note that $y_{i t}=0$ at $\operatorname{MobPen}_{i t} / M_{i}^{*}=1 / 2$ and this is also the point of fastest growth in absolute terms. The factors determining the timing and speed of diffusion are specified as: ${ }^{20}$

$$
\begin{aligned}
& a_{i t}=\alpha_{i}^{0}+\sum_{n=2}^{\overline{\mathrm{N}}} \alpha^{n} \mathrm{~N}_{i t}^{n}+\sum_{j \in J} \alpha^{j} D_{i t}^{j}+x_{i t} \alpha \\
& b_{i t}=\beta_{i}^{0}+\sum_{n=2}^{\overline{\mathrm{N}}} \beta^{n} \mathrm{~N}_{i t}^{n}+\sum_{j \in J} \beta^{j} D_{i t}^{j}+x_{i t} \beta
\end{aligned}
$$

$\alpha_{i}^{0}$ is the individual fixed effect for each country $i$, and is determined by each country's initial position of network adoption. $\overline{\mathrm{N}}$ is the maximum number of firms observed. $\mathrm{N}_{i t}^{n}$ is the set of market structure dummies equal to one when the number of firms equals $n$, monopoly is the baseline rate of diffusion, $D_{i t}^{j}$ is a set of $J$ regulatory, ownership and technology dummy variables and $x_{i t}$ is a vector of continuously measured variables that influence diffusion (e.g. consumer prosperity).

Following Gruber and Verboven (2001b) we consider restrictions on the coefficients of discrete (dummy) variables such that there are no artificially imposed sharp jumps in penetration immediately upon some regulatory change. For example, if penetration is the same the moment before privatization when $D_{i t}^{\mathrm{Pr} v}=0$ as it is after privatization when $D_{i t}^{\mathrm{Pr} v}=1$, we require $\alpha^{\operatorname{Pr} v}=-\beta^{\operatorname{Pr} v} T_{i}^{\operatorname{Pr} v}$. Substituting into (3), and (3) and (4) into (2), results in a single term in privatization: $\beta^{\operatorname{Prv}} D_{i}^{\operatorname{Pr} v}\left[t-T_{i}^{\operatorname{Pr} v}\right]$. We later test this and other sets of restrictions against the data.

Gruber and Verboven only consider a single entry while we observe multiple entry events. We provide a generalisation of the parameter constraints necessary to avoid discontinuities as each subsequent firm enters. ${ }^{21}$ Write $T_{i}^{n}$ as the year of entry of the $n$ 'th firm in country $i$.

\footnotetext{
${ }^{19}$ This is determined by unobserved demographic, social, political and technological factors.

${ }^{20}$ This follows Gruber and Verboven (2001b).

${ }^{21}$ In effect, we estimate a spline function with 'knots' tying the existing level of diffusion around each new entry.
} 
Assuming no artificially imposed jump in penetration on second entry at $t=T_{i}^{2}$, the monopoly penetration at that specific time (but not thereafter) is the same as the duopoly penetration: $\alpha^{2}=-\beta^{2} T_{i}^{2}$. Substitution into (2) provides a single term in $\mathrm{N}_{i}^{2}: \beta^{2} \mathrm{~N}_{i}^{2}\left[t-T_{i}^{2}\right]$. For smooth transition on third entry at $t=T_{i}^{3}$, penetration must be the same immediately before and after entry, so $\beta^{2}\left[T_{i}^{3}-T_{i}^{2}\right]=\alpha^{3}+\beta^{3} T_{i}^{3}$. This requires $\alpha^{3}=\beta^{2}\left[T_{i}^{3}-T_{i}^{2}\right]-\beta^{3} T_{i}^{3}$ and substituting into (2) we have two terms: $\beta^{2}\left[T_{i}^{3}-T_{i}^{2}\right]+\beta^{3}\left[t-T_{i}^{3}\right]$. The first term provides the start point for triopoly following the period of duopoly, and the second term is the triopoly effect. Continuing the pattern, we obtain the general restriction for smooth transitions, each locking in the achievements of the preceding market structure: $\alpha^{n}=\left\{\sum_{k=2}^{n-1} \beta^{k}\left[T_{i}^{k+1}-T_{i}^{k}\right]\right\}-\beta^{n} T_{i}^{n}$. Substituting into (2), we have

$$
y_{i t}=\alpha_{i}^{0}+x_{i t} \alpha+\left[\beta_{i}^{0}+x_{i t} \beta\right] t+\sum_{n=2}^{\overline{\mathrm{N}}} \beta^{n} N_{i t}^{n}+\sum_{j \in J} \beta^{j} D_{i t}^{j}\left[t-T_{i}^{j}\right]+u_{i}+\varepsilon_{i t}
$$

where $N_{i t}^{n}=\left\{\mathrm{N}_{i t}^{n}\left[t-T_{i}^{n}\right]+\sum_{k=n+1}^{\overline{\mathrm{N}}} \mathrm{N}_{i t}^{k}\left[T_{i}^{n+1}-T_{i}^{n}\right]\right\}$. Note that for all $t \geq T_{i}^{n+1}, N_{i t}^{n}=\left[T_{i}^{n+1}-T_{i}^{n}\right]$. Thus, the history of earlier market structures matters because it provides the starting point from which market penetration grows in the new competitive environment. ${ }^{22}$

The intuition behind the construction of our market structure variables, $N_{i t}^{n}$, is illustrated in Figure $2 \mathrm{a}^{23}$ The market opens with a monopoly at $t=T_{i}^{1}$, which is generally before our dataset starts (at $t=0$ ). This and the initial penetration locate the diffusion curve. The duopoly curve is steeper if duopoly diffusion is faster than under monopoly but our constraint means that there is no discrete jump at $T_{i}^{2}$. The rate of diffusion may also fall with entry as illustrated in the figure with the entry of the fourth firm.

\section{Figs. $2 a$ and $2 b$ near here}

Finally, we allow for catch-up in two dimensions: $\alpha_{i}^{0}=\alpha^{0}-\gamma T_{i}^{1}$ and $\beta_{i}^{0}=\beta^{0}+\lambda T_{i}^{1} .^{24}$ Substituting into (5) and rearranging, we estimate:

\footnotetext{
${ }^{22}$ As reported below, we find statistical support for this set of market structure restrictions, and for the ownership and regulation events, but not for the introduction of digital technology.
${ }^{23}$ Note that unlike Figure 1, Figures $2 \mathrm{a}$ and $2 \mathrm{~b}$ have the logistic transformation, $\mathrm{y}$, on the vertical axis. This linearises the diffusion curve for any given market structure or start date.

${ }^{24}$ If the market was opened before 1991 , then $T_{i}^{1}<0$.
} 
$y_{i t}=\alpha^{0}+x_{i t} \alpha+x_{i t} t \beta+\sum_{n=2}^{\overline{\mathrm{N}}} \beta^{n} N_{i t}^{n}+\sum_{j \in J} \beta^{j} D_{i t}^{j}\left[t-T_{i}^{j}\right]+\gamma\left[t-T_{i}^{1}\right]+\left[\beta^{0}-\gamma\right] t+\lambda T_{i}^{1} t+u_{i}+\varepsilon_{i t}$

Figure $2 b$ illustrates the effects of a late start with country B issuing its first licence at a later date than country A. Ceteris paribus, $\lambda>0$ measures the extent to which the speed of diffusion for earlier starters is less than for those starting at $t=0 . \quad \gamma>0$ measures the extent to which late starters have not yet caught up by $t=0$. Later starters have a higher initial penetration as long as $T_{i}^{1}>-\left[\beta^{0}-\gamma+x_{i T_{i}^{1}} \beta\right] / \lambda$. There is full catch-up at $t=\bar{T}=\gamma / \lambda$.

\section{Data and measurement}

The dependent variable is a logistic transformation of mobile network penetration (MobPen) measured by the number of mobile phone subscribers per 100 inhabitants as reported by the International Telecommunications Union (ITU) for our panel of 30 countries over 16 years $(1991-2006){ }^{25}$ Cross-country averages are reported in Table 1 alongside fixed line penetration to provide perspective. The cross-country range of penetration rates and average growth curve are shown in Figure 1. Table 1 also shows fixed line penetration for comparison. Average mobile penetration overtook fixed line in 2000.

The logistic transformation in (2) requires an assumption about the maximal level of adoption, $M_{i}^{*}$. Our baseline assumption is that this is $100 \%$ of the population. Some countries in our sample have achieved a mobile penetration rate exceeding $100 \%$ in recent years. This is due to multiple-subscriptions with different networks (e.g. separate private and work mobiles) and is likely to follow a different dynamic to initial take-up. We sensitivity-test different values for a common saturation level in two ways: either excluding observations from our dataset once penetration reaches $100 \%$; or retaining them but capping observed penetration rates at a maximum of $99 \%$. In our econometrics, we find that neither the values nor the significance of estimated coefficients are substantially changed by using these alternatives. For convenience, in the text we only report results for the former. Results for the full capped sample are reported in Appendix A-2

Most national mobile network markets were a monopoly in 1991 (see Table 2). ${ }^{26}$ The number of duopolies grew until 1998, peaking at 19 countries. The last three monopolies were

\footnotetext{
${ }^{25}$ The Greek market did not open until 1993 and Poland opened in 1992.

${ }^{26}$ The information on the number of mobile network operators (MNOs) in each national market year-by-year are collected from the OECD (for data from 1990 to 2000) and from countries' telecom regulators' websites as well as from some MNOs' websites (for data from 2000 to 2006). See OECD report: DSTI/ICCP/TISP(99)11/FINAL, online available at: http://www.oecd.org/dataoecd/54/42/2538118.pdf
} 
eliminated a year later and by 2000, 19 out of the 30 countries had at least three operators. By 2006, there were only three duopolies left (including China). The average number of mobile network operators grew from 1.2 to 3.8 over the period. All but one of our observations of six or seven firm market structures are for the USA, with Canada in 2006 being the other one. Since there are few such observations, we combine market structures with six or seven firms in our econometric estimation. The coefficients on our market structure variables measure the additional speed of diffusion for each market structure relative to monopoly.

\section{Tables 1, 2 and 3 near here}

Privatization (Prv) is measured as a dummy variable that equals one if at least $50 \%$ of assets were held by the private sector for the full year, and equals zero otherwise. Just $17 \%$ of mobile network operators were private in 1991 but this grew to $90 \%$ by 2003. The year in which mobile providers were privatized in each country is given in Table 3 , with 14 countries privatizing in 1996-98. ${ }^{27}$ We require a full year of privatization because the change of ownership may take place late in a year. We adopt the same principle for the establishment of an independent regulator and entry of a network operator. Since the most recent full privatization, which was of the Korean mobile market in 2002, there are only three countries (i.e. China, Mexico and Turkey) where the mobile incumbents are still state-owned.

We define a regulator as independent only if it is backed by legislation and can claim operational decision-making independent of any other government body. ${ }^{28}$ As can be seen from Table 3, the establishment of an independent regulator is fairly closely related to privatization, but there are some significant differences in timing. An equal number (eleven) were established before and after privatization, though three of the latter were before the start of our sample (see Table 3). Four independent regulators were established in the same year as privatization and four countries have yet to establish an independent regulator. Independent regulation (IndReg) is measured as a dummy variable that equals one if present and zero otherwise.

For reasons explained in the previous section, we include two time trends and an interaction in our specification. Timeopen $\left(=t-T_{i}^{1}\right)$ is country-specific and starts with the first full year that the market opened. The coefficient on this term, $\gamma$, picks up the higher adoption rate of early

\footnotetext{
${ }^{27}$ The information on the year (and ownership level) at which the incumbent mobile network operators were privatized in each country are extracted from the ITU-BDT and the World Bank's online telecom regulatory databases. Available on: http://www.itu.int/ITU-D/ICTEYE/Regulators/Regulators.aspx and http://rru.worldbank.org/Privatization/.

${ }^{28}$ The information on the year and conditions when an independent regulatory authority was established in each country are extracted from the ITU-BDT online telecom regulatory database. Available on: http://www.itu.int/ITUD/ICTEYE/Regulators/Regulators.aspx\#.
} 
starters in 1991. The sum of the coefficients on Time $(=t)$ and Timeopen is $\beta^{0}$ which provides the baseline monopoly diffusion rate (excluding other time-related effects). The coefficient on the interaction $t^{*} T_{i}^{1}$ is $\lambda$ which picks up the faster rate of diffusion for late starters.

We include two continuous demand-side variables explaining adoption and diffusion. We expect to observe positive income effects (measured by GDPpc) on the initial level of diffusion, but there may be a negative coefficient on GDPpc*t if poorer countries catch-up richer ones. ${ }^{29}$ Previous studies have also found the degree of urbanisation, Urban, to influence diffusion. Urban dwellers may have better access to fixed line services including public phone services, and so find less added value in a mobile service. As with income, there may be later catch-up by urban dwellers but it is possible that the comparative advantage of mobiles remains low.

We also include a set of mobile network technology variables capturing the impacts of technological advance and technological standards on mobile telephony adaption. ${ }^{30}$ We observe, in sequence, three network technology eras covered by our data period: analogue (only), mixed analogue and digital technologies, and digital (only). We define the analogue (only) era as the period before digital took at least $5 \%$ of the national mobile market share. Similarly, we define the digital (only) era to have started once it had achieved (at least) 95\% market share. With analogue (only) as the base case, we have two mutually exclusive technology dummies: mixed technology (DigMix) equals one if digital has between 5\% and 95\% market share and zero otherwise; and DigOnly equals one in the digital (only) era and zero otherwise. We also calculate a Herfindahl index of technology standards (HHItech). This includes multiple standards within analogue and digital, as well as between generations. We expect DigOnly to boost diffusion as it introduced new services (e.g. SMS) and provided more reliability and privacy. The mixed era (DigMix) should have a similar effect unless potential consumers were confused or held back to see whether digital would indeed dominate technology. In practice, hold-back or confusion were unlikely during the digital transition because its advantages were clear and well publicised. However, these concerns may have been more substantial for multiple standards within a technology generation (e.g. multiple digital standards). Thus, we expect a positive coefficient on HHItech if standardisation promotes adoption.

Prices are excluded from our core model in order to focus on the effect of market structure. Complex pricing schemes also make it difficult to summarise price in a single number. Nevertheless, we investigate one dimension of price in order to gain insight into arguably the

\footnotetext{
${ }^{29}$ Data are taken from the International Monetary Fund.

${ }^{30}$ The information on mobile network technologies is extracted from WCIS World Cellular Information Service. Available on: http://www.wcisplus.com.
} 
most important mechanism through which market structure effects may operate. Data are available for 'standard' calls and we use this to examine the extent to which market structure and regulation effects operate through price level as distinct from the other elements of the consumer offer.

Mobile service price (MobPrice) is measured simply by the cost of 3-minute local call. ${ }^{31}$ In practice, consumers face alternative pricing plans so this single indicator captures only one dimension of a possibly complex set of tariffs. The mobile call price was relatively stable 199197, then declined sharply until 2001, after which it began to rise again (see Table 1). Over the full period, there has been an average annual decrease of $2 \%$ pa. The average fixed-line price of a 3-minute local call, FLPrice (as reported by ITU), is also included to test for possible complementarities or a substitution effect between fixed and mobile usages. Complementarities may arise early in the diffusion process because fixed line call termination opportunities are relatively important for a subscriber. As mobile penetration increases, however, mobile-tomobile calls become more important and the substitution effect with fixed line services may dominate. When mobile price is included directly in our model, we adopt instrumental variable estimation methods to take account of the likely endogeneity of MobPrice due to strategies used by firms to encourage early uptake. We include three variables as additional instruments for identification: lagged mobile service price (i.e., the mobile service price of the previous year); labour productivity in mobile services (i.e. the number of mobile phone subscribers served per person employed in the mobile service segment); and national population (Pop) to capture potential market size and possible economies of scale. Labour productivity is an attractive instrument as it is an important cost driver that must be expected to affect price, yet there is no reason to expect it to affect diffusion directly.

A summary of the variables and their definitions is given in Table 4.

Table 4 near here

\section{Empirical results and discussion}

\subsection{Market structure}

We have already argued that licensing policy determines entry and that detailed case studies suggest this has been determined by a political process (see section 2). It remains possible that regulators may be emulating market forces, for example by releasing more licences in larger markets. If this were the case, our estimation of the diffusion equation should take account of the endogeneity of market structure. We adopt a two stage approach to assess this possibility.

\footnotetext{
${ }^{31}$ This is as reported by the ITU. Prices are adjusted for inflation and converted into USD\$.
} 
First, we estimate a simple model of market structure to test our hypothesis that it is not determined by standard market forces. Second, we conduct an endogeneity test for market structure in a modified diffusion equation. ${ }^{32}$

We consider a simple empirical model of the number of entrants drawing on the economics of endogenous market structure (e.g. Bresnahan and Reiss, 1991; Sutton, 1997). Theory predicts that the number of firms should increase with market size if entry is endogenous and competition is not predominantly through overhead investments in quality. Population (lnPop) is a widely used measure of potential market size (e.g. Bresnahan and Reiss, 1991) and alongside other variables such as per capita GDP $(\ln G D P p c)$ and years since the market opened (TimeOpen), it provides a strongly grounded measure of market size. ${ }^{33}$ If we were to find that these variables determined mobile network market structure, it would both confirm the necessity for instrumental variable estimation techniques because market structure would likely be correlated with the error in the diffusion equation, and point to suitable instruments to apply in the diffusion equation. Population is a particularly attractive potential instrument because there is no reason to expect the maximum scale of the market to have an independent influence on diffusion (i.e. other than through any effect on market structure). ${ }^{34}$

The theory of market structure also predicts that markets with lower exogenous overhead costs will have more entry. In the context of mobile networks, some capital equipment may be internationally sourced but other overheads will depend on local productivity, in which case we should expect a positive relationship between the number of firms and the productivity of local network firms (lnMobProd). This is a potentially valid instrument because there is no reason to expect productivity to affect diffusion directly (i.e. other than through market structure or price).

If, on the other hand, the number of networks is determined not so much by market forces as by a regulator allocating scarce spectrum, then we should expect to see a response to technological developments that relax the spectrum constraint. The key development was digital

\footnotetext{
${ }^{32}$ It turns out that the endogeneity test is superfluous because of the results from the market structure estimation.

${ }^{33}$ The robust relationship between population and market structure in a wide range of markets with free entry has been confirmed by a large body of empirical research over the last two decades. Recent examples include Manuszak and Moul (2008) and Berry and Waldfogel (2010).

${ }^{34}$ Diffusion is measured proportionately, so larger markets, ceteris paribus, should not have a different diffusion rate to smaller markets. For example, the empirical papers discussed earlier do not use population to determine the rate of diffusion, though population is sometimes used to estimate the maximum scale of the market (e.g. Gruber and Verboven, 2001a).
} 
technology which became available internationally at the same time, independent of the stage of diffusion. $^{35}$

Several alternative econometric approaches have been developed to investigate the determinants of market structure, including the estimation of market size thresholds for the entry of each number of firms (Bresnahan and Reiss, 1991). ${ }^{36}$ Such methods rely on a strong relationship between market structure and market size, which should also be present in a direct regression of the number of firms on market size. More sophisticated methods are unlikely to be worthwhile if there is no relationship in simple regressions with the number of firms $(N F)$ or the $\log$ number $(\ln N F)$ as dependent variables. The right hand side variables include those discussed above and all non-market structure variables in the diffusion regression. Since China is by far the largest country but has retained a duopoly structure, we estimate the model both with and without China to ensure that its inclusion does not distort our conclusions. The results are presented in Table 5.

\section{Table 5 near here}

Box-Cox tests suggest that $\operatorname{lnNF}$ is the more appropriate specification for the dependent variable, so we focus on those results. The first column reports the full sample results and the second column excludes China. The results are similar. InPop is not even close to statistically significant and has a perversely negative coefficient even when China is excluded. Both $\ln G D P p c$ and time since first entry (Timeopen) similarly have insignificant coefficients (negative for $\ln G D P p c$ ). On the cost side, labour productivity (InMobProd) also has the opposite sign to that predicted by the theory of endogenous market structure, though it is insignificant. ${ }^{37}$

In contrast, we find support for a regulated entry story based on technology and a global trend. The advent of digital (DigMix $=1$ ) added another firm (on average) to an existing duopoly, with no additional effect once the transition from analogue was complete (DigOnly = 1). A single standard $($ HHItech $=1)$ is associated with more firms than if there are competing standards. Real time (Time) provides a strongly significant positive influence.

\footnotetext{
${ }^{35}$ There may also be international differences in political economy, with some countries being more inclined to facilitate entry than others. To try to capture this, we collected a measure of general business freedom and expected a positive relation with the number of firms. This measure was taken from the Index of Economic Freedom, which is constructed annually from 1995 and published by The Wall Street Journal and The Heritage Foundation; it is available at http://www.heritage.org/index/explore. However, this measure was never significant and it reduced sample size as it was not available prior to 1995 , so we do not report the results.

${ }^{36}$ For recent developments see, for example, Mazzeo (2002) and Manuszak and Moul (2008). An alternative approach is Sutton's (1997) bounds estimation of the relationship between market structure and market size.

${ }^{37}$ A possible explanation is that an exogenous increase in the number of firms pushes providers up their cost curves. Our results are not changed if we drop lnMobProd from the regression.
} 
The results for the $N F$ are very similar. The only changes are that HHItech becomes insignificant and MobProd becomes significant. In the light of these results, and particularly the total insignificance of InPop as a potential instrument, it is unsurprising that a Hausman endogeneity test for panel instrumental models (Hausman, 1978; Hausman and Taylor, 1981) does not support instrumental estimation of a modified diffusion equation. ${ }^{38}$ We conclude that there is no evidence of mobile network market structure being endogenous to the diffusion process. Given these findings, it would be inefficient to use instrumental variable estimates for market structure in the diffusion model. ${ }^{39}$

\subsection{Diffusion}

We next report our panel estimates of equation (6). Hausman tests reject random effects in favour of fixed effects, so all reported results are estimated with fixed effects. ${ }^{40}$ F-tests support our smooth transition restrictions for all discrete variables except the technology dummies. ${ }^{41}$ Table 6 presents our estimates. The first two columns report the model without price. The exclusion of China, with one minor exception discussed below, makes very little difference so we focus on the full sample.

Market structures with two, three and five firms each have a significantly faster diffusion rate as compared with monopoly. Pentopoly is the fastest, followed by triopoly then duopoly. ${ }^{42}$ The strong significance of these market structures is robust across specifications, as are the insignificance of tetropoly and market structures with six or seven firms. ${ }^{43}$ The quantitative significance of market structure is substantial and depends on the current level of mobile penetration. $^{44}$ Pentopoly penetrates the market at a maximum of 6.5 percentage points per

\footnotetext{
${ }^{38}$ For the purpose of this test, we treated the number of firms as a continuous $x$ variable in equation (4) and suppressed the terms in $N$. See Appendix A-4. The number of firms has a significant positive coefficient with or without IV estimation, but increases in size if instrumented. However, the Hausman test rejects endogeneity in every specification (i.e. both the $\ln N F$ and $N F$ specifications, each with and without China).

${ }^{39}$ The inefficiency of IV estimators in these circumstances can be large. See Bound et al (1995).

${ }^{40}$ Reported t-statistics and significance tests are based on robust standard errors.

${ }^{41}$ Model specification test results are reported in Appendix A-1.

${ }^{42}$ F-tests on core Model find that there is no significant difference between the coefficients associated with triopoly and pentopoly, with $\mathrm{F}=2.97<\mathrm{F}(1,398)=3.84$; whereas, they do have a significantly greater effect on diffusion than duopoly $(\mathrm{F}=3.95)$.

${ }^{43}$ We have no convincing explanation for the tetropoly result. The $N=6 \& 7$ result may be due to this being almost exclusively a US market structure which was introduced very sharply (see Table 2).

${ }^{44}$ This can be seen by noting: $\frac{d M o b P e n_{i t}}{d x}=\left[\frac{\text { obPen }_{i t}}{100}\right]\left[100-\right.$ MobPen $\left._{i t}\right] \frac{d y_{i t}}{d x}$.
} 
annum faster than monopoly ceteris paribus when penetration is around 50\%, and 4.2 percentage points faster when penetration is around either $20 \%$ or $80 \%$.

\section{Table 6 near here}

Privatization is a strongly significant and positive influence on mobile diffusion. In the absence of an independent regulator, a coefficient of 0.09 translates into an incremental boost to the diffusion rate of 2.2 percentage points when penetration is around 50\%, and of 1.4 percentage points at penetration of $20 \%$ or $80 \%$. There is an additional, but quantitatively smaller, positive impact of independent regulation. The combined effect of privatization and independent regulation is equivalent to moving from monopoly to duopoly.

All the income and urbanisation coefficients are strongly significant. A one standard deviation increase in $\ln G D P p c$ is associated with a 1.0 percentage point increase in 1991 penetration around the average $2 \%$. However, this is the only coefficient that is substantially affected by the exclusion of China: it becomes smaller and loses significance. On the basis of the full sample results, this GDP 'advantage' is gradually eroded with no ceteris paribus difference between countries of different incomes by 2003 (or 1999 if China is excluded). Urbanisation has an even stronger effect, with 2.7 percentage point higher penetration in 1991 if a country is one standard deviation more rural. There is no catch-up for urban areas as the diffusion speed declines with urbanisation.

Digital technology provided a significant boost to mobile penetration, of similar magnitude to a move from monopoly to pentopoly. Closer inspection of our results also reveals some interesting detail. In Western Europe, significant digital penetration (i.e. DigMix $=1$ ) started in 1994 (i.e. Time = 3). Combining the coefficients on DigMix and DigMix*t, there is a smooth acceleration of penetration with the advent of digital. The scale of this effect is similar to the difference between monopoly and pentopoly. By the time digital has become dominant (i.e. DigOnly $=1$ and DigMix =0), there is a very small and fairly smooth reduction in the digital effect. $^{45}$

There was little variation in transmission technologies in the analogue era, but some countries standardised quickly in the digital era (e.g. Western Europe) while others (e.g. USA) did not. From $1995(t=4)$, the positive coefficient on HHItech $* t$ means that failure to standardise resulted in slower diffusion than in countries with a standardised technology. As a rough order of magnitude, moving from three distinct technologies with equal market shares to a single standard has a similar effect to the introduction of digital in terms of the speed of diffusion.

\footnotetext{
${ }^{45}$ For example, if digital began to dominate in $2000(\mathrm{t}=9)$, the DigMix effect in that year is $-0.75+9 * 0.258=1.57$, and the DigOnly effect is $0.042+9 * 0.191=1.76$, but thereafter the diffusion speed is 0.07 slower.
} 
Each of the trend variables is highly significant. In combination, they suggest a substantial baseline speed of diffusion, around seven times the maximum marginal market structure or digital effects. The estimated parameters are such that ceteris paribus earlier starters have a lower initial penetration (i.e. as drawn in Fig. 2b). The coefficient on TimeOpen estimates the average penetration advantage in 1991 from each year's earlier (or later) start. This suggests an increase (or decrease) of 0.56 percentage points around $2 \%$ penetration. Recalling that catch-up following a late start is achieved at $t=\bar{T}=\gamma / \lambda$, our estimates suggest ceteris paribus late-start catch-up will be achieved in 2014.

We next consider, with due caution, the role of prices. The caution derives from the fact that it is very hard to capture price structures in a single price of a 3-minute call, and there are additional, standard problems of adjusting for inflation and exchange rates. Nevertheless, the third and fourth columns of Table 6 investigate call price effects with and without instrumental variable estimation. We focus on the instrumented results in column three because there are both theoretical and statistical reasons to expect price to be endogenous. Table 7 reports the identifying instruments from a first stage fixed effects regression of price on all the RHS variables in Table 6 (except mobile price) and these additional instruments. Both lagged price and InMobProd are significant at the $1 \%$ level, but population is insignificant. The same holds whether or not China is included in the sample. Hausman tests further support our treatment of price as endogenous. ${ }^{46}$

\section{Table 7 near here}

Higher mobile prices significantly slow diffusion, though this effect is eroded over time. High price markets appeared to catch up with low price markets by 2005. Compared with the non-instrumented regression reported in the last column of Table 6, the price effect is much stronger, with a larger negative effect. This is intuitively consistent with networks pursuing a strategy of penetration pricing and raising price once more consumers have adopted. The positive sign on fixed-line prices is consistent with fixed and mobile being substitutes, but the lack of significance suggests caution in drawing such a conclusion. Inasmuch as market structure and regulation effects work through price, we should expect the inclusion of mobile prices to reduce the impact of those variables. This is what we find as both the size of coefficients and significance of the market structure and independent regulation variables are much reduced. Nevertheless, there remains a market structure effect for triopoly and especially pentopoly, which suggests there are non-price elements to the marketing offer stimulated by competition. We also note that both the size and significance of the privatization variable are

\footnotetext{
${ }^{46}$ Full test results are reported in Appendix A-5.
} 
enhanced, which is consistent with stronger non-price marketing effects in the offer of privatized firms.

\subsection{Comparison with existing literature}

The paper closest to ours is Gruber and Verboven $(\mathrm{GV}, 2001 \mathrm{~b}){ }^{47}$ Their estimation period is 1981-97 so they only observe the very early period of diffusion. They do not distinguish the number of competitors, but do investigate the introduction of first competition, which they find to be more effective in the digital era than for analogue. With the hindsight provided by our more recent data, our results suggest that the number of firms does matter and that the larger number of licences in the digital era may help explain GV's results. Both GV and the current paper find additional effect of digital technology boosting diffusion, though we estimate a stronger effect. This boost is consistent with the greater services digital technology can provide.

$\mathrm{GV}$ also find slower diffusion when there are competing digital systems but their dummy variable is insignificant. Our Herfindahl index of technologies estimates a similar effect much more precisely. This suggests that standard setting is beneficial to diffusion. While there is no evidence that competing standards provide any longer term advantage, it remains possible that they may be beneficial for 'next generation' innovation.

Our estimate of late-start convergence in 2014 is within the range of GV's estimates. We also find similar location and diffusion speed effects of GDP per capita. Overall, our results are largely consistent with GV but we have been able to confirm some of their findings, extend understanding of digital and multiple standards, and add considerably to the examination of market structure and regulatory effects.

\section{Conclusions}

The aim of this paper is to identify the structural features of a partly regulated market that provide the best competitive environment to maximise the market penetration of a new product mobile telephony. Unlike earlier studies, we are able to use data that covers the core period of the diffusion process. Our specification does not impose a functional form on the effects of alternative numbers of mobile networks. Like earlier studies, we confirm the benefit of moving from monopoly to duopoly, but the advantage of using more recent data is that we now have experience of a much wider range of market structures. This reveals that pentopoly (i.e. five firms) is a major competitive improvement on duopoly but there is no further improvement in

\footnotetext{
${ }^{47}$ It is not meaningful to compare our results to other papers on mobile diffusion which do not estimate impacts on the speed of diffusion. For example, Liikanen et al (2004) focus on maximum penetration and Koski and Kretschmer (2005) on the 'location' effects.
} 
diffusion with more firms. More provisionally, we find that market structure effects do not appear to operate exclusively through prices - there are other elements of the product offer, also related to market structure, that affect consumer uptake.

It is interesting to relate this to the wider empirical literature that relates market structure and competitive outcomes. Much of this now exploits data on local geographical markets to investigate the implied effects of competition on margins, price and productivity. ${ }^{48}$ An emerging stylised fact is that a relatively small number of firms, often between two and four depending on the product, is sufficient to generate most of the benefits of competition in traditional homogeneous product markets (e.g. professional services, retailing, concrete). That research uses genuinely local markets (compared with national markets in this paper) to provide the crosssection dimension. It also investigates totally different dependent variables. Nevertheless, our results are consistent with the view that relatively few firms may be sufficient for competition in relatively homogeneous product markets.

There is an important difference between mobile networks and more traditional markets because spectrum limitations have been addressed by strict licensing of operators. This eliminates the threat of entry as a mechanism by which competition works. The institutional response has been that mobile networks are typically regulated, though the independence of the regulator has varied across countries and over time. We find that the independence of the regulator has a positive role to play in addition to market structure. In line with some of the earlier literature, privatization also has a substantial positive impact on diffusion.

Our findings are consistent with the view that a balance may need to be struck between investment incentives for network industries characterised by large sunk costs and the benefits of an apparently more competitive market structure, but this balance may require five firms. This is particularly relevant when determining the number of spectrum licenses to be granted, but it is also relevant for merger policy. Our findings additionally support the view that private ownership and independent regulation are also desirable in the absence of an entry threat.

Our results also cast light on how consumers respond to competition between multiple standards. We find that diffusion is faster when there is standardisation. This may be due to either customer confusion or rational delay in adoption until a dominant network technology emerges.

Finally, the data in this paper covers the core period of diffusion in thirty countries. Average market penetration across these countries rose from less than $2 \%$ to nearly $97 \%$ in sixteen years. As the mobile network market matures, the consumer focus naturally turns to usage and product

\footnotetext{
${ }^{48}$ For example, Bresnahan and Reiss (1991), Manuszak and Moul (2008) and Syverson (2004).
} 
development. ${ }^{49}$ It is not obvious that competition at the mature stages of the product life cycle will be determined in the same way as at the diffusion stage. However, new products are always emerging and it remains important to have developed a more complete view of the role of competition in the diffusion process of a new consumer product.

${ }^{49}$ See Grajek and Kretschmer (2009) for a study of usage over different technological generations. 


\section{References}

Armstrong, M., Sappington, D.E.M., 2006. Regulation, Competition, and Liberalization. Journal of Economic Literature. 44, 325-366.

Berry, S., Waldfogel, J., 2010. Product Quality and Market Size. Journal of Industrial Economics. LVIII.1, 1-31.

Bound, J., Jaeger, D.A., Baker, R.M., 1995. Problems with Instrumental Variables Estimation when the Correlation between the Instruments and the Endogenous Explanatory Variable is Weak. Journal of the American Statistical Association. 90, 443-450.

Boylaud, O., Nicoletti, G., 2001. Regulation, Market Structure and Performance in Telecommunications. OECD Economic Studies. 32, 99-142.

Bresnahan, T.F., Reiss, P.C., 1991. Entry and Competition in Concentrated Markets. Journal of Political Economy. 99, 977-1009.

Cubbin, J., Stern, J., 2006. The Impact of Regulatory Governance and Privatization on Electricity Industry Generation Capacity in Developing Economies. World Bank Economic Review. 20, 115141.

Fink, C., Mattoo, A., Rathindran, R., 2001. Liberalizing Basic Telecommunications: The Asian Experience. World Bank Policy Research Working Paper Series No. 2718.

Gasmi, F., Noumba, P., Virto, L.R., 2006. Political Accountability and Regulatory Performance in Infrastructure Industries: An Empirical Analysis. World Bank Policy Research Working Paper Series No. 4101.

Geroski, P.A., 2000. Models of technology diffusion. Research Policy. 29 (4-5), 603-625.

Grajeck, M., Kretschmer, T. 2009. Usage and Diffusion of Cellular Telephony, 1998-2004. International Journal of Industrial Organization. 27, 238-249.

Griliches, Z., 1957. Hybrid Corn: An Exploration in the Economics of Technological Change. Econometrica. 25, 501-522.

Gruber, H., Verboven, F., 2001a. The Diffusion of Mobile Telecommunications Services in the European Union. European Economic Review. 45, 577-588.

---- 2001b. The evolution of markets under entry and standards regulation - the case of global mobile telecommunications. International Journal of Industrial Organization. 19, 1189-1212.

Gual, J., Trillas, F., 2003. Telecommunications Policies: Determinants and Impacts. IESE Working Paper No. D/510. London Business School, University of Navarra.

Gutierrez, L., 2003a. Regulatory Governance in the Latin American Telecommunications Sector. Utilities Policy. 11, 225-240.

---- 2003b. The Effect of Endogenous Regulation on Telecommunications Expansion and Efficiency in Latin America. Journal of Regulatory Economics. 23, 257-286.

Gutierrez ,L.H., Berg, S., 2000. Telecommunications Liberalization and Regulatory Governance: Lessons from Latin America. Telecommunications Policy. 24, 865-884. 
Hausman, J.A., 1978. Specification Tests in Econometrics. Econometrica. 46, 1251-1271.

---- 1997. Valuing the Effect of Regulation on New Services in Telecommunications. Brooking Papers on Economic Activity. Microeconomics.

Hausman, J.A., Taylor, W.E., 1981. Panel Data and Unobserved Individual Effects. Econometrica. 49, $1377-1398$.

Koski, H., Kretschmer, T., 2005. Entry Standards and Competition: Firm Strategies and the Diffusion of Mobile Telephony. Review of Industrial Organization. 26, 89-113.

Levy, B., Spiller, P., 1994. The Institutional Foundations of Regulatory Commitment: A Comparative Analysis of Telecommunications Regulation. Journal of Law, Economics and Organization. 10, 201 246.

---- 1996. Regulations, institutions, and commitment: Comparative studies of telecommunications. Cambridge University Press: Cambridge.

Li, W., Xu, L.C., 2002. The Political Economy of Privatization and Competition Cross-Country Evidence from the Telecommunications Sector. Journal of Comparative Economics. 30, 439-462.

---- 2004. The Impact of Privatization and Competition in the Telecommunications Sector around the World. Journal of Law and Economics. 47, 395-430.

Liikanen J., Toivanen, O., Stoneman P., 2004. Intergenerational Effects in the Diffusion of New Technology. The International Journal of Industrial Organisation. 22, 1137 - 1154.

Maiorano, F., Stern, J., 2007. Institutions and Telecommunications Infrastructure in Low and MiddleIncome Countries: The Case of Mobile Telephony. Utilities Policy. 15, 165-181.

Manuszak, M.D., Moul, C.C., 2008. Prices and Market Structure in Office Supply Superstores. Journal of Industrial Economics. LVI.1, 94-112.

Mansfield, E., 1961. Technical Change and the Rate of Imitation. Econometrica. 29, 741-766.

Mazzeo, M.J., 2002, 'Competitive Outcomes in Product-Differentiated Oligopoly', Review of Economics and Statistics, 84, 716-728.

Megginson, W.L., Netter, J.M., 2001. From State to Market: A Survey of Empirical Studies on Privatization. Journal of Economic Literature. 39, 321-389.

McNary, R., 2001. The Network Penetration Effects of Telecommunications Privatization and Competition. Public Policy. 58, 222-235.

North, D., 1990. Institutions, Institutional Change and Economic Performance. Harvard University Press: Cambridge, MA.

Parker, D., Kirkpatrick, C., 2005. Privatisation in Developing Countries: A Review of the Evidence and the Policy Lessons. Journal of Development Studies. 41, 513-541.

Ramamurti, R.A., 2000. Multilevel Model of Privatization in Emerging Economies. Academy of Management Review. 25, 525-550.

Ros, A.J., 1999. Does Ownership or Competition Matter? The Effects of Telecommunications Reform on Network Expansion and Efficiency. Journal of Regulatory Economics. 15, 65-92. 
---- 2003. The Impact of the Regulatory Process and Price Cap Regulation in Latin American Telecommunications Markets. Review of Network Economics. 2, 270-286.

Stern, J., Holder, S., 1999. Regulatory Governance: Criteria for Assessing the Performance of Regulatory Systems. Utilities Policy. 8, 33-50.

Sutton, J., 1997. Sunk Costs and Market Structure, MIT Press.

Sutton, J., 2000. Technology and Market Structure, MIT Press.

Syverson, C., 2004. Market Structure and Productivity: A Concrete Example. Journal of Political Economy. 112, 1181-1222.

Villalonga, B., 2000. Privatization and Efficiency: Differentiating Ownership Effects from Political, Organizational, and Dynamic Effects. Journal of Economic Behavior \& Organization. 42, 43-74.

Wallsten, S.J., 2001. An Econometric Analysis of Telecom Competition, Privatization and Regulation in Africa and Latin America. Journal of Industrial Economics. 49, 1-20.

---- 2004. Privatizing Monopolies in Developing Countries: The Real Effects of Exclusivity Periods in Telecommunications. Journal of Regulatory Economics. 26, 303-320.

Yarrow, G., 1986. Privatization in Theory and Practice. Economic Policy. 1, 323-377. 
Table 1: Summary Statistics for Cross-Country Trends in Telecoms in 30 Countries (1991-2006)

\begin{tabular}{|c|c|c|c|c|c|c|c|}
\hline & $\begin{array}{c}\text { Mobile } \\
\text { penetration } \%\end{array}$ & $\begin{array}{c}\text { Fixed-line } \\
\text { penetration } \%\end{array}$ & $\begin{array}{l}\text { Mobile price } \\
\text { of 3-min } \\
\text { local call } \\
\text { (USD) }\end{array}$ & $\begin{array}{l}\text { Number } \\
\text { MNOs }\end{array}$ & $\begin{array}{c}\text { Mobile } \\
\text { incumbents } \\
\text { privatized }\end{array}$ & $\begin{array}{l}\text { Independent } \\
\text { regulator } \\
\text { established }\end{array}$ & $\begin{array}{c}\text { Privatization \& } \\
\text { independent } \\
\text { regulator }\end{array}$ \\
\hline year & \multicolumn{7}{|c|}{ Mean } \\
\hline 191991 & 1.66 & "39.21 & 1.36 & 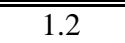 & $17 \%$ & $20 \%$ & $10 \%$ \\
\hline 1992 & 2.11 & 40.40 & 1.44 & 1.2 & $20 \%$ & $20 \%$ & $10 \%$ \\
\hline 1993 & 2.88 & 41.60 & 1.38 & 1.5 & $23 \%$ & $23 \%$ & $10 \%$ \\
\hline 1994 & 4.49 & 42.84 & 1.40 & 1.6 & $27 \%$ & $27 \%$ & $10 \%$ \\
\hline 1995 & 7.14 & 44.10 & 1.42 & 1.8 & $33 \%$ & $30 \%$ & $10 \%$ \\
\hline 1996 & 11.03 & 45.53 & 1.45 & 1.9 & $37 \%$ & $30 \%$ & $13 \%$ \\
\hline 1997 & 15.91 & 47.38 & 1.31 & 2.2 & $50 \%$ & $37 \%$ & $23 \%$ \\
\hline 1998 & 24.22 & 48.27 & 1.22 & 2.4 & $60 \%$ & $60 \%$ & $37 \%$ \\
\hline 1999 & 37.57 & 49.79 & 1.04 & 2.9 & $83 \%$ & $67 \%$ & $57 \%$ \\
\hline 2000 & 52.87 & 50.83 & 0.94 & 3.1 & $83 \%$ & $70 \%$ & $60 \%$ \\
\hline 2001 & 63.85 & 50.47 & 0.77 & 3.5 & $87 \%$ & $80 \%$ & $70 \%$ \\
\hline 2002 & 70.09 & 50.09 & 0.89 & 3.4 & $87 \%$ & $83 \%$ & $73 \%$ \\
\hline 2003 & 76.15 & 49.30 & 0.99 & 3.5 & $90 \%$ & $87 \%$ & $80 \%$ \\
\hline 2004 & 83.72 & 48.81 & 0.98 & 3.5 & $90 \%$ & $87 \%$ & $80 \%$ \\
\hline 2005 & 90.30 & 47.34 & 1.00 & 3.7 & $90 \%$ & $87 \%$ & $80 \%$ \\
\hline 2006 & 96.79 & 46.87 & 1.00 & 3.8 & $90 \%$ & $87 \%$ & $80 \%$ \\
\hline $\begin{array}{l}\text { Average annual } \\
\text { change rate }\end{array}$ & $33 \%$ & $1 \%$ & $-2 \%$ & $8 \%$ & $12 \%$ & $11 \%$ & $17 \%$ \\
\hline
\end{tabular}

Data source: based on a variety of sources, including ITU database on the world telecommunication/ICT indicators (2006), ITU-BDT online regulatory information database, OECD regulatory database (2000), countries' telecom regulators' websites and mobile network operators' websites. See text for details. 
Table 2: The Number of Mobile Network Operators by Country from 1991 to 2006

\begin{tabular}{|c|c|c|c|c|c|c|c|c|c|c|c|c|c|c|c|c|c|}
\hline & & 1991 & 1992 & 1993 & 1994 & 1995 & 1996 & 1997 & 1998 & 1999 & 2000 & 2001 & 2002 & 2003 & 2004 & 2005 & 2006 \\
\hline 1 & "China & $\overline{c 1}$ & $\overline{c 1}$ & 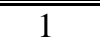 & 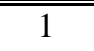 & 2 & 2 & 2 & 2 & 2 & 2 & 2 & 2 & 2 & 2 & 2 & 2 \\
\hline 2 & Australia & 1 & 1 & 1 & 3 & 3 & 3 & 3 & 3 & 3 & 4 & 4 & 4 & 5 & 4 & 4 & 4 \\
\hline 3 & Austria & 1 & 1 & 1 & 1 & 1 & 1 & 1 & 2 & 3 & 3 & 3 & 3 & 3 & 3 & 5 & 4 \\
\hline 4 & Belgium & 1 & 1 & 1 & 1 & 1 & 2 & 2 & 2 & 2 & 2 & 3 & 3 & 3 & 4 & 5 & 5 \\
\hline 5 & Canada & 2 & 2 & 2 & 2 & 2 & 2 & 3 & 4 & 4 & 4 & 4 & 4 & 4 & 4 & 5 & 6 \\
\hline 6 & Czech Republic & 1 & 1 & 1 & 1 & 1 & 1 & 2 & 2 & 2 & 2 & 3 & 3 & 3 & 3 & 3 & 4 \\
\hline 7 & Denmark & 1 & 1 & 2 & 2 & 2 & 2 & 2 & 2 & 4 & 4 & 4 & 5 & 5 & 5 & 5 & 4 \\
\hline 8 & Finland & 1 & 1 & 2 & 2 & 2 & 2 & 2 & 2 & 4 & 4 & 4 & 4 & 4 & 4 & 4 & 4 \\
\hline 9 & France & 2 & 2 & 2 & 2 & 2 & 2 & 2 & 2 & 2 & 2 & 3 & 3 & 3 & 4 & 4 & 4 \\
\hline 10 & Germany & 1 & 1 & 2 & 2 & 3 & 3 & 3 & 3 & 4 & 4 & 4 & 4 & 4 & 4 & 4 & 4 \\
\hline 11 & Greece & 0 & 0 & 2 & 2 & 2 & 2 & 2 & 2 & 3 & 3 & 3 & 3 & 3 & 3 & 3 & 3 \\
\hline 12 & Hungary & 1 & 1 & 1 & 1 & 2 & 2 & 2 & 2 & 2 & 2 & 4 & 3 & 3 & 3 & 3 & 3 \\
\hline 13 & Iceland & 1 & 1 & 1 & 1 & 1 & 1 & 1 & 1 & 2 & 2 & 2 & 3 & 3 & 3 & 3 & 4 \\
\hline 14 & Ireland & 1 & 1 & 1 & 1 & 1 & 1 & 1 & 2 & 2 & 2 & 3 & 3 & 3 & 3 & 3 & 4 \\
\hline 15 & Italy & 1 & 1 & 1 & 1 & 1 & 1 & 2 & 2 & 2 & 3 & 4 & 4 & 4 & 4 & 4 & 4 \\
\hline 16 & Japan & 2 & 2 & 2 & 2 & 2 & 3 & 4 & 4 & 4 & 4 & 4 & 4 & 4 & 4 & 5 & 5 \\
\hline 17 & Korea & 1 & 1 & 1 & 1 & 1 & 1 & 2 & 5 & 5 & 5 & 5 & 3 & 3 & 3 & 3 & 3 \\
\hline 18 & Luxembourg & 1 & 1 & 1 & 1 & 1 & 1 & 1 & 1 & 2 & 2 & 3 & 3 & 3 & 3 & 3 & 3 \\
\hline 19 & Mexico & 2 & 2 & 2 & 2 & 2 & 2 & 2 & 2 & 2 & 3 & 4 & 4 & 4 & 4 & 4 & 4 \\
\hline 20 & Netherlands & 1 & 1 & 1 & 1 & 1 & 1 & 2 & 2 & 4 & 5 & 5 & 5 & 5 & 5 & 5 & 5 \\
\hline 21 & New Zealand & 1 & 1 & 1 & 2 & 2 & 2 & 2 & 2 & 2 & 2 & 2 & 2 & 2 & 2 & 2 & 2 \\
\hline 22 & Norway & 1 & 1 & 1 & 2 & 2 & 2 & 2 & 2 & 2 & 2 & 2 & 2 & 2 & 2 & 2 & 2 \\
\hline 23 & Poland & 1 & 1 & 2 & 2 & 2 & 2 & 2 & 2 & 3 & 3 & 3 & 3 & 3 & 3 & 3 & 3 \\
\hline 24 & Portugal & 1 & 1 & 2 & 2 & 2 & 2 & 2 & 2 & 3 & 3 & 3 & 3 & 3 & 3 & 3 & 3 \\
\hline 25 & Spain & 1 & 1 & 1 & 1 & 2 & 2 & 2 & 2 & 2 & 3 & 3 & 3 & 3 & 3 & 3 & 3 \\
\hline 26 & Sweden & 2 & 2 & 3 & 3 & 3 & 3 & 3 & 3 & 3 & 3 & 4 & 4 & 4 & 4 & 4 & 4 \\
\hline 27 & Switzerland & 1 & 1 & 1 & 1 & 1 & 1 & 1 & 1 & 2 & 3 & 3 & 3 & 3 & 3 & 4 & 4 \\
\hline 28 & Turkey & 1 & 1 & 1 & 1 & 2 & 2 & 2 & 2 & 2 & 2 & 2 & 2 & 2 & 2 & 3 & 3 \\
\hline 29 & United Kingdom & 2 & 2 & 2 & 3 & 4 & 4 & 4 & 4 & 4 & 4 & 4 & 4 & 4 & 5 & 5 & 5 \\
\hline 30 & United States & 2 & 2 & 2 & 2 & 2 & 3 & 6 & 6 & 7 & 7 & 7 & 7 & 7 & 7 & 6 & 6 \\
\hline & Total & 36 & 36 & 44 & 49 & 55 & 58 & 67 & 73 & 88 & 94 & 104 & 103 & 104 & 106 & 112 & 114 \\
\hline & Average & 1.2 & 1.2 & 1.5 & 1.6 & 1.8 & 1.9 & 2.2 & 2.4 & 2.9 & 3.1 & 3.5 & 3.4 & 3.5 & 3.5 & 3.7 & 3.8 \\
\hline
\end{tabular}

Data source: compiled by author based on a variety of sources, including OECD regulatory database, countries' telecom regulators' websites and mobile network operators' websites 
Table 3: Summary Statistics for Mobile Sector Developments by Country

\begin{tabular}{|c|c|c|c|c|c|c|c|}
\hline \multirow{2}{*}{ Country } & \multirow{2}{*}{$\begin{array}{c}\text { Year } \\
\text { incumbents } \\
\text { privatized }\end{array}$} & \multirow{2}{*}{$\begin{array}{c}\text { Year } \\
\text { independent } \\
\text { regulator } \\
\text { established } \\
\end{array}$} & \multirow{2}{*}{$\begin{array}{l}\text { Number } \\
\text { MNOs in } \\
2006\end{array}$} & \multicolumn{3}{|c|}{$\begin{array}{c}\text { Mobile penetration (\%) over } \\
\text { 1991-2006 } \\
\end{array}$} & \multirow{2}{*}{$\begin{array}{c}\text { HHI of } \\
\text { mobile } \\
\text { network } \\
\text { technology } \\
\end{array}$} \\
\hline & & & & 1991 & 1999 & 2006 & \\
\hline "Australia & 1997 & 1997 & 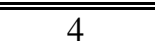 & 1.7 & 333.4 & 96.3 & 0.80 \\
\hline Austria & 1998 & 1997 & 4 & 1.5 & 53.2 & $>100$ & 0.87 \\
\hline Belgium & 1996 & 1993 & 5 & 0.5 & 31.1 & 92.1 & 0.94 \\
\hline Canada & always & 1976 & 6 & 2.8 & 22.7 & 52.3 & 0.63 \\
\hline China & $\mathrm{n} / \mathrm{a}$ & $\mathrm{n} / \mathrm{a}$ & 2 & 0.004 & 3.4 & 35.1 & 0.79 \\
\hline Czech Republic & 1994 & 2000 & 4 & 0.012 & 18.9 & $>100$ & 0.94 \\
\hline Denmark & 1991 & dep. & 4 & 3.4 & 49.5 & $>100$ & 0.85 \\
\hline Finland & 1998 & 1988 & 4 & 6.3 & 63.4 & $>100$ & 0.86 \\
\hline France & 1997 & 1997 & 4 & 0.66 & 36.6 & 84.6 & 0.90 \\
\hline Germany & 1996 & 1998 & 4 & 0.7 & 28.5 & $>100$ & 0.87 \\
\hline Greece & 1996 & 1992 & 3 & $0.5^{*}$ & 36.7 & 99.9 & 0.87 \\
\hline Hungary & 1993 & 1999 & 3 & 0.08 & 16.1 & 99.1 & 0.89 \\
\hline Iceland & 1997 & 1997 & 4 & 5.0 & 61.9 & $>100$ & 0.80 \\
\hline Ireland & 1996 & 2002 & 4 & 0.9 & 44.8 & $>100$ & 0.87 \\
\hline Italy & 1998 & 1998 & 4 & 1.0 & 52.8 & $>100$ & 0.84 \\
\hline Japan & always & $\mathrm{n} / \mathrm{a}$ & 5 & 1.1 & 44.9 & 79.7 & 0.63 \\
\hline Korea & 2002 & 1997 & 3 & 0.38 & 51.3 & 83.0 & 0.94 \\
\hline Luxemburg & 1998 & 1997 & 3 & 0.29 & 48.4 & $>100$ & 0.97 \\
\hline Mexico & $\mathrm{n} / \mathrm{a}$ & 1996 & 4 & 0.18 & 7.9 & 54.7 & 0.73 \\
\hline Netherlands & 1994 & 1997 & 5 & 0.8 & 42.5 & 96.7 & 0.89 \\
\hline New Zealand & always & 2001 & 2 & 2.1 & 36.4 & 85.6 & 0.61 \\
\hline Norway & 1998 & 1987 & 2 & 5.5 & 59.5 & $>100$ & 0.84 \\
\hline Poland & 1998 & 2000 & 3 & $0.006^{*}$ & 10.2 & 96.4 & 0.86 \\
\hline Portugal & 1995 & 1989 & 3 & 0.13 & 46.7 & $>100$ & 0.89 \\
\hline Spain & 1992 & 1996 & 3 & 0.28 & 37.3 & $>100$ & 0.90 \\
\hline Sweden & 2000 & 1992 & 4 & 6.6 & 57.8 & $>100$ & 0.82 \\
\hline Switzerland & 1998 & dep. & 4 & 2.5 & 42.6 & 99.7 & 0.90 \\
\hline Turkey & $\mathrm{n} / \mathrm{a}$ & 2000 & 3 & 0.082 & 12.1 & 72.2 & 0.91 \\
\hline UK & always & 1984 & 5 & 2.2 & 45.7 & $>100$ & 0.87 \\
\hline US & always & 1934 & 6 & 3.0 & 30.8 & 77.9 & 0.61 \\
\hline $\begin{array}{l}\text { Average across } \\
\text { country }\end{array}$ & -- & -- & 3.8 & 1.7 & 37.6 & 96.8 & 0.84 \\
\hline $\begin{array}{l}\text { Data source: auth } \\
\text { countries' telecom } \\
* \text { The mobile netwo } \\
\text { 1.n/a: event yet to o } \\
\text { 2. Dep.: a separate } 1 \\
\text { 3. Privatization is } \\
\text { Independent reg } \\
\text { decision making. }\end{array}$ & $\begin{array}{l}\text { compiled base } \\
\text { gulators'websi } \\
\text { market for Gre } \\
\text { ur; } \\
\text { zulator is subjec } \\
\text { corded for those } \\
\text { lator is recorde }\end{array}$ & $\begin{array}{l}\text { on a variety of } \\
\text { s and mobile net } \\
\text { ce and Poland sta } \\
\\
\text { o several other g } \\
\text { ore at least } 50 \% \\
\text { only if it is creat }\end{array}$ & $\begin{array}{l}\text { ources, incl } \\
\text { ork operator } \\
\text { ed in } 1993 \text { a } \\
\text { vernmental b } \\
\text { of assets of s } \\
d \text { backed by }\end{array}$ & $\begin{array}{l}\text { g ITU-B } \\
\text { vebsites. S } \\
1992 \text { resp } \\
\text { es in its d } \\
\text {-owned c } \\
\text { slation an }\end{array}$ & $\begin{array}{l}\text { nline re } \\
\text { ct. } \\
y \text {. } \\
\text { n makin } \\
\text { nies hav } \\
\text { ms to b }\end{array}$ & ry infor & $\begin{array}{l}\text { e sector; } \\
\text { ernments in }\end{array}$ \\
\hline
\end{tabular}


Table 4: Summary of Variables

\begin{tabular}{|c|c|c|c|}
\hline Variables & Abbreviation & Description & Source \\
\hline Diffusion & $y_{i t}$ & $\begin{array}{l}\text { Logistically transformed number } \\
\text { of mobile subscribers per } 100 \\
\text { inhabitants }\end{array}$ & ITU \\
\hline Regulation & $\begin{array}{c}N_{i t} \\
\operatorname{IndReg}_{i t} \\
\operatorname{Prv}_{i t}\end{array}$ & $\begin{array}{l}\text { Market structure variables } \\
\text { (defined following equation (5)) } \\
\text { which can be interpreted as a } \\
\text { dummy variable equal to } 1 \text { for } \\
\text { that number of firms } \\
\text { Dummy variable for independent } \\
\text { regulator: } 1 \text {, if created backed by } \\
\text { legislation and independent of } \\
\text { government; } 0 \text {, otherwise. } \\
\text { Dummy variable for privatization: } \\
1 \text {, if at least } 50 \% \text { of assets held by } \\
\text { private sector; } 0 \text {, otherwise. }\end{array}$ & $\begin{array}{c}\text { ITU, WB, OECD, regulators' \& MNOs' } \\
\text { websites }\end{array}$ \\
\hline $\begin{array}{l}\text { Network } \\
\text { technology }\end{array}$ & $\begin{array}{l}\text { DigOnly }_{i t} \\
\text { DigMix }_{i t}\end{array}$ & $\begin{array}{l}\text { Dummy variable for digital and } \\
\text { equivalent technology: } 1 \text {, if only } \\
\text { digital or equivalent technology } \\
\text { used for mobile network } \\
\text { operation; } 0 \text {, otherwise. } \\
\text { Dummy variable for both } \\
\text { analogue and digital technologies: } \\
1 \text {, if both analogue and digital } \\
\text { technologies used simultaneously } \\
\text { for mobile network operation; } 0 \text {, } \\
\text { otherwise. } \\
\text { Herfindahl-Hirschman Index of } \\
\text { mobile network technology } \\
\text { concentration }\end{array}$ & WCIS \\
\hline \multirow{2}{*}{$\begin{array}{l}\text { Demand } \\
\text { variables }\end{array}$} & \multirow{2}{*}{ 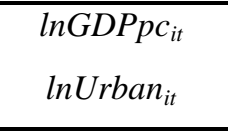 } & \multirow{2}{*}{$\begin{array}{l}\text { Per capita GDP. } \\
\text { Urban population as a } \% \text { of total } \\
\text { national population. }\end{array}$} & IMF \\
\hline & & & WBG-HNP \\
\hline $\begin{array}{l}\text { Trend and } \\
\text { catch-up }\end{array}$ & $\begin{array}{c}\text { TimeOpen }_{i} \\
\text { Time } \\
T_{i}{ }^{*} t \\
T\end{array}$ & $\begin{array}{l}\text { Time since mobile market opened. } \\
\text { Standard time trend }(t) \text {. } \\
\text { Interaction between year of first } \\
\text { operation of mobile market and } \\
\text { standard time trend. } \\
\text { Time since the event with which it } \\
\text { is interacted (e.g. privatization) }\end{array}$ & \\
\hline Prices & $\begin{array}{c}\text { lnMobPrice }_{i t} \\
\text { lnFLPrice }_{i t}\end{array}$ & $\begin{array}{l}\text { Mobile price of } 3 \text {-minute local } \\
\text { call. } \\
\text { Fixed-line price of } 3 \text {-minute local } \\
\text { call. }\end{array}$ & ITU \\
\hline \multirow{3}{*}{$\begin{array}{l}\text { Additional } \\
\text { instrumental } \\
\text { variables }\end{array}$} & \multirow{3}{*}{$\begin{array}{c}\operatorname{lnPop}_{i t} \\
\text { lnMobProd }_{i t} \\
\text { lnLIMobPrice }_{i t}\end{array}$} & \multirow{3}{*}{$\begin{array}{l}\text { Total national population. } \\
\text { Number of mobile subscribers } \\
\text { served employee. } \\
\text { 1-year lagged mobile price of } 3 \text { - } \\
\text { minute local call. }\end{array}$} & WBG-HNP \\
\hline & & & ITU \& MII \\
\hline & & & ITU \\
\hline
\end{tabular}


Table 5: Number of firms and potential market size

\begin{tabular}{|c|c|c|c|c|}
\hline \multirow[t]{2}{*}{ Dependent Variable: } & \multicolumn{2}{|l|}{$\ln \mathbf{N F}$} & \multicolumn{2}{|l|}{ NF } \\
\hline & w. China & w.o. China & w. China & w.o. China \\
\hline \multirow[t]{2}{*}{ lnGDPpc } & -0.361 & "-0.188 & -1.485 & -0.912 \\
\hline & -1.20 & -0.60 & -1.27 & -1.20 \\
\hline \multirow[t]{2}{*}{$\operatorname{lnPop}$} & 0.014 & -0.355 & -0.593 & -1.830 \\
\hline & 0.01 & -0.35 & -0.20 & -0.58 \\
\hline \multirow[t]{2}{*}{$\operatorname{lnUrban}$} & 0.568 & 1.733 & 1.341 & 5.280 \\
\hline & 0.51 & 0.94 & 0.38 & 0.88 \\
\hline \multirow[t]{2}{*}{ Prv } & 0.080 & 0.071 & 0.061 & 0.039 \\
\hline & 0.82 & 0.73 & 0.24 & 0.15 \\
\hline \multirow{2}{*}{ IndReg } & 0.069 & 0.073 & 0.129 & 0.146 \\
\hline & 0.77 & 0.84 & 0.55 & 0.65 \\
\hline \multirow[t]{2}{*}{$\operatorname{lnMobProd}$} & -0.027 & -0.030 & $-0.165 * *$ & $-0.173 * *$ \\
\hline & -1.20 & -1.27 & -2.18 & -2.22 \\
\hline \multirow[t]{2}{*}{ DigOnly } & $0.450 * * *$ & $0.442 * * *$ & $1.128 * * *$ & $1.121 * * *$ \\
\hline & 3.54 & 3.36 & 3.22 & 3.12 \\
\hline \multirow[t]{2}{*}{ DigMix } & $0.457 * * *$ & $0.435 * * *$ & $0.881 * * *$ & $0.834 * * *$ \\
\hline & 4.60 & 4.21 & 3.21 & 2.96 \\
\hline \multirow[t]{2}{*}{ HHItech } & $0.494 * * *$ & $0.459 * * *$ & 0.503 & 0.384 \\
\hline & 2.74 & 2.50 & 0.89 & 0.67 \\
\hline \multirow[t]{2}{*}{ Time } & $0.076^{* * *}$ & $0.069 * * *$ & $0.255 * * *$ & $0.232 * * *$ \\
\hline & 5.02 & 4.48 & 5.55 & 5.61 \\
\hline \multirow[t]{4}{*}{ TimeOpen } & 0.001 & 0.001 & -0.079 & $-0.085^{*}$ \\
\hline & 0.06 & 0.03 & -1.31 & -1.41 \\
\hline & $\mathrm{n}=447$ & $\mathrm{n}=431$ & $\mathrm{n}=447$ & $\mathrm{n}=431$ \\
\hline & $\begin{array}{l}\text { R-sq = } 0.7531 \\
\text { (within) }\end{array}$ & $\begin{array}{l}\text { R-sq = } 0.7540 \\
\text { (within) }\end{array}$ & $\begin{array}{l}\text { R-sq = } 0.6942 \\
\text { (within) }\end{array}$ & $\begin{array}{l}\text { R-sq = } 0.6985 \\
\text { (within) }\end{array}$ \\
\hline Estimation Procedure & $\mathrm{FE}$ & FE & FE & FE \\
\hline
\end{tabular}

Note: In all models, ***, **, and * indicate significant levels at $1 \%, 5 \%$, and $10 \%$, respectively; $\mathrm{t}$-statistics are reported below each coefficient in italic type. 
Table 6: Estimation Results under Panel Fixed-effects and Panel Instrumental Approaches Dependent variable: $y_{i t}=\ln \left(\right.$ MobPen $_{i t} /\left(100-\right.$ MobPen $\left.\left._{i t}\right)\right)$

\begin{tabular}{|c|c|c|c|c|}
\hline & \multicolumn{2}{|c|}{ Core Model } & \multicolumn{2}{|c|}{ Model incl. Price } \\
\hline & w. China & w.o. China & w. instruments & w.o. instruments \\
\hline \multicolumn{5}{|l|}{ Market structure: } \\
\hline \multirow[t]{2}{*}{$\mathrm{N}=2$} & $0.119 * *$ & $0.113 * *$ & 0.065 & $0.098 *$ \\
\hline & 2.08 & 1.89 & 1.03 & 1.64 \\
\hline \multirow[t]{2}{*}{$\mathrm{N}=3$} & $0.158 * * *$ & $0.148 * * *$ & $0.111 *$ & $0.141 * *$ \\
\hline & 2.58 & 2.34 & 1.62 & 2.16 \\
\hline \multirow[t]{2}{*}{$\mathrm{N}=4$} & 0.012 & -0.004 & -0.033 & -0.015 \\
\hline & 0.22 & -0.06 & -0.51 & -0.25 \\
\hline \multirow[t]{2}{*}{$\mathrm{N}=5$} & $0.261 * * *$ & $0.258 * * *$ & $0.213 * * *$ & $0.247 * * *$ \\
\hline & 3.96 & 3.86 & 2.92 & 3.55 \\
\hline \multirow[t]{2}{*}{$\mathrm{N}=6 \& 7$} & 0.053 & 0.048 & -0.068 & 0.006 \\
\hline & 0.67 & 0.59 & -0.77 & 0.07 \\
\hline \multicolumn{5}{|c|}{ Ownership and regulation: } \\
\hline \multirow[t]{2}{*}{ Prv*T } & $0.088 * * *$ & $0.078 * * *$ & $0.121 * * *$ & $0.103 * * *$ \\
\hline & 3.56 & 3.04 & 4.44 & 4.00 \\
\hline \multirow{2}{*}{ IndReg*T } & $0.030 * *$ & $0.029^{*}$ & 0.021 & $0.027 *$ \\
\hline & 1.72 & 1.60 & 1.13 & 1.55 \\
\hline \multicolumn{5}{|l|}{ Demand: } \\
\hline \multirow{2}{*}{$\operatorname{lnGDPpc}$} & $0.892 * *$ & 0.496 & $1.759 * * *$ & $1.158 * *$ \\
\hline & 1.83 & 0.88 & 3.12 & 2.26 \\
\hline \multirow[t]{2}{*}{$\operatorname{lnGDPpc} * \mathrm{t}$} & $-0.072 * * *$ & $-0.059 * * *$ & $-0.111 * * *$ & $-0.082 * * *$ \\
\hline & -3.39 & -2.62 & -4.37 & -3.56 \\
\hline \multirow{2}{*}{ lnUrban } & $-6.924 * * *$ & $-8.510 * * *$ & $-4.097 * *$ & $-6.099 * * *$ \\
\hline & -4.14 & -3.83 & -2.15 & -3.50 \\
\hline \multirow[t]{2}{*}{$\operatorname{lnUrban} * \mathrm{t}$} & $-0.272 * * *$ & $-0.261 * * *$ & $-0.191 * * *$ & $-0.246 * * *$ \\
\hline & -5.19 & -4.88 & -3.26 & -4.55 \\
\hline \multicolumn{5}{|l|}{ Technology: } \\
\hline DigMix & $-0.750 * * *$ & $-0.765 * * *$ & $-0.698 * * *$ & $-0.687 * * *$ \\
\hline & -3.00 & -2.97 & -2.67 & -2.73 \\
\hline $\operatorname{DigMix} * \mathrm{t}$ & $0.258 * * *$ & $0.270 * * *$ & $0.272 * * *$ & $0.247 * * *$ \\
\hline & 5.32 & 5.42 & 5.20 & 4.96 \\
\hline DigOnly & 0.042 & 0.059 & -0.179 & 0.056 \\
\hline & 0.17 & 0.23 & -0.62 & 0.21 \\
\hline DigOnly*t & $0.191 * * *$ & $0.201 * * *$ & $0.237 * * *$ & $0.187 * * *$ \\
\hline & 3.90 & 4.02 & 4.25 & 3.63 \\
\hline HHItech & $-1.445 * * *$ & $-1.498 * * *$ & $-1.019 *$ & $-1.228 * *$ \\
\hline & -2.57 & -2.58 & -1.72 & -2.17 \\
\hline HHItech*t & $0.352 * * *$ & $0.363 * * *$ & $0.285 * * *$ & $0.310 * * *$ \\
\hline & 6.11 & 6.12 & 4.43 & 5.06 \\
\hline Trend growth and ca & ch-up: & & & \\
\hline TimeOpen & $0.284 * * *$ & $0.262 * * *$ & $0.289 * * *$ & $0.277 * * *$ \\
\hline & 4.11 & 3.69 & 3.85 & 3.85 \\
\hline Time & $1.761 * * *$ & $1.605 * * *$ & $1.675 * * *$ & $1.747 * * *$ \\
\hline & 5.84 & 5.04 & 4.95 & 5.38 \\
\hline $\mathrm{T} 1 * \mathrm{t}$ & $0.012 * * *$ & $0.013 * * *$ & $0.010 * * *$ & $0.011 * * *$ \\
\hline & 5.06 & 5.26 & 3.66 & 4.53 \\
\hline Price: & & & & \\
\hline lnMobPrice & & & $-1.908 * * *$ & $-0.525 * *$ \\
\hline & & & -3.92 & -2.14 \\
\hline $\operatorname{lnMobPrice}{ }^{*} \mathrm{t}$ & & & $0.132 * * *$ & 0.019 \\
\hline & & & 3.04 & 0.72 \\
\hline lnFLPrice & & & 2.370 & 0.688 \\
\hline & & & 1.22 & 0.38 \\
\hline $\operatorname{lnFLPrice}{ }^{*} \mathrm{t}$ & & & 0.116 & 0.122 \\
\hline & & & 0.77 & 0.85 \\
\hline & $\mathrm{n}=447$ & $\mathrm{n}=431$ & $\mathrm{n}=447$ & $\mathrm{n}=447$ \\
\hline & R-sq $=0.9600$ (within) & $\mathrm{R}$-sq $=0.9588$ (within) & R-sq = 0.9608 (within) & $\mathrm{R}-\mathrm{sq}=0.9576$ (within) \\
\hline Estimation Procedure & $\mathrm{FE}$ & $\mathrm{FE}$ & FEIV & $\mathrm{FE}$ \\
\hline
\end{tabular}


Table 7: Additional instruments for mobile price

\begin{tabular}{lll}
\hline & \multicolumn{2}{l}{$\ln$ MobPrice } \\
\cline { 2 - 3 } & w. China & w.o. China \\
\hline \hline lnL1MobPrice & $0.533^{* * *}$ & $0.531 * * *$ \\
lnMobProd & 8.47 & 8.44 \\
& $-0.050^{* * *}$ & $-0.049 * * *$ \\
lnPop & -3.02 & -2.85 \\
& 0.135 & 0.247 \\
\hline & 0.29 & 0.43 \\
\hline \multirow{2}{*}{ Estimation Procedure } & $\mathrm{n}=447$ & $\mathrm{n}=431$ \\
\hline
\end{tabular}

Note: In all models, ***,**, and * indicate significant levels at $1 \%, 5 \%$, and $10 \%$, respectively; t-statistics are reported below each coefficient in italic type. Both regressions also included all the RHS variables in Table 6 (excluding lnMobPrice and its interaction with time).

See Appendix A-3 for the full first-stage regression results.

Figure 1: Growth of mobile network penetration

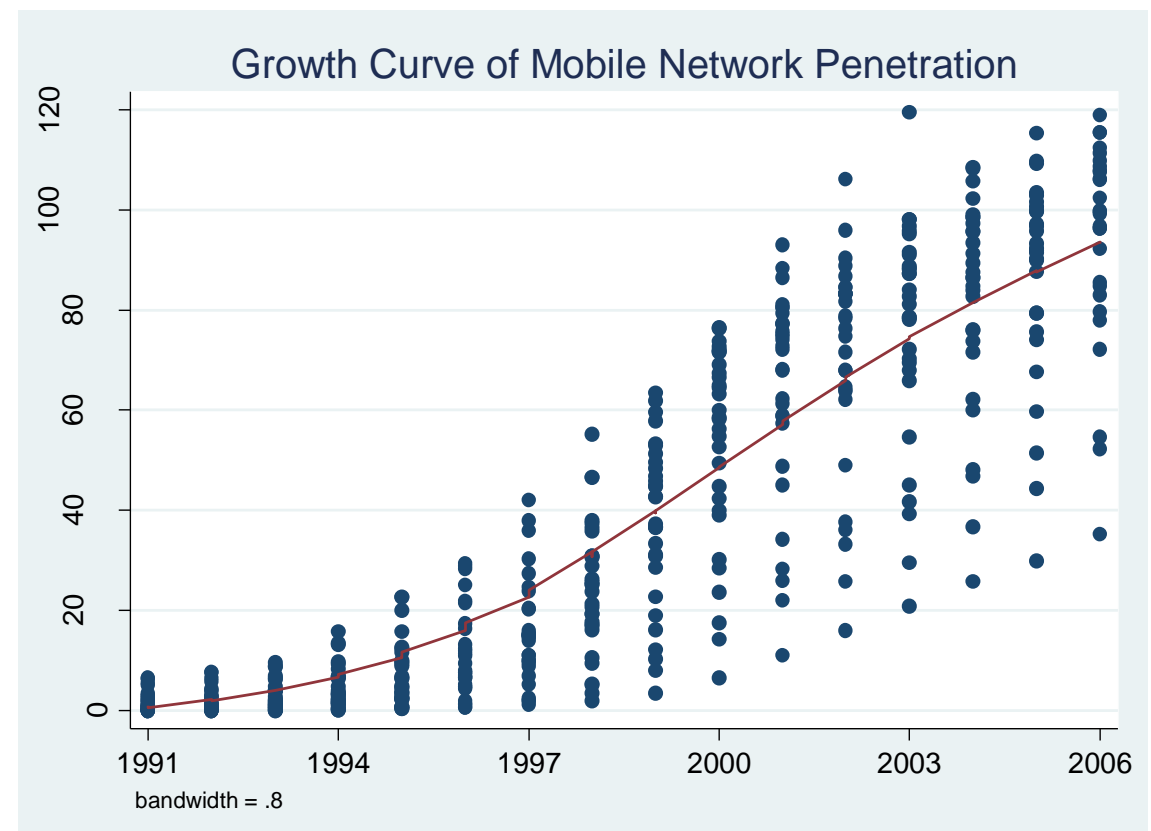

Note: Each dot represents one of the 30 countries in our sample. The line connects the mean penetration rate across 30 countries in each year. 
Figure 2a: Diffusion and market structure (illustrative)

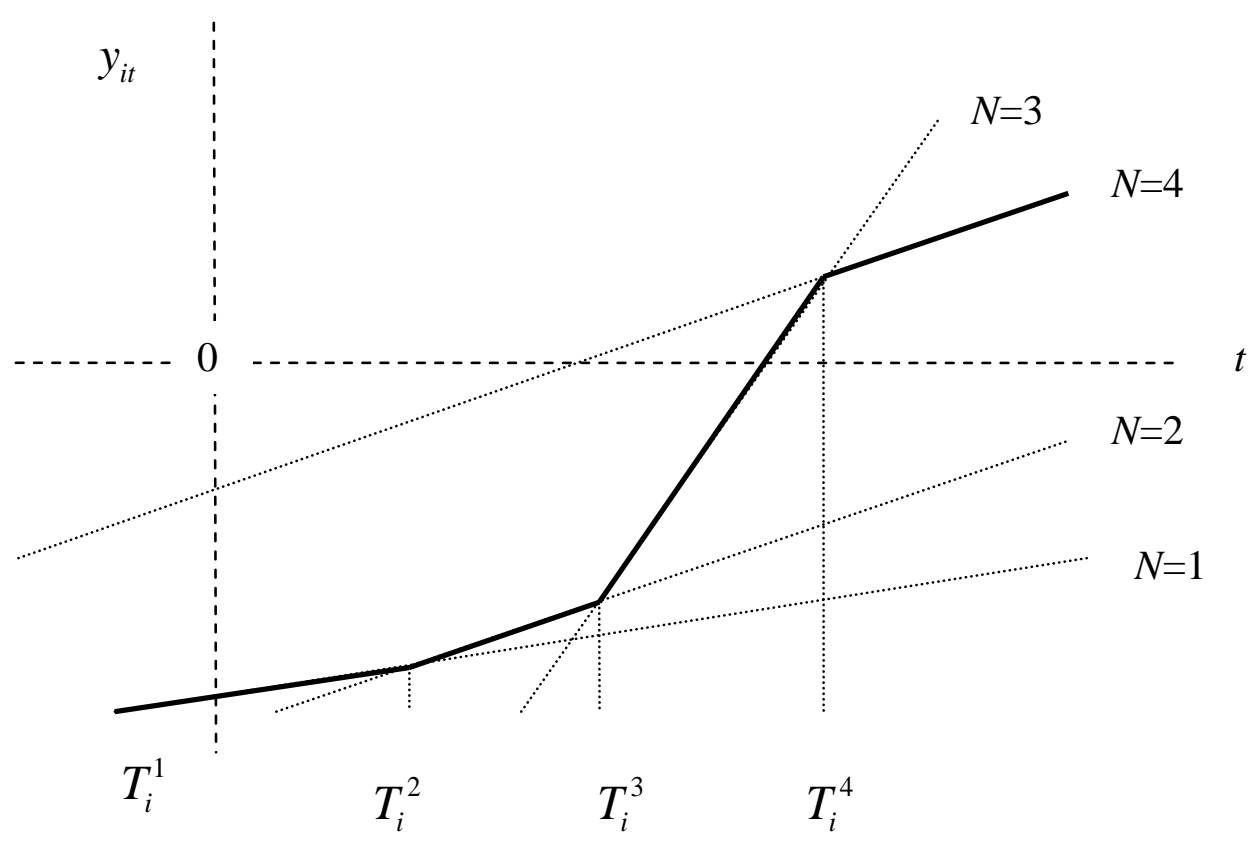

Figure 2b: Catch-up by country B following a late start (illustrative)

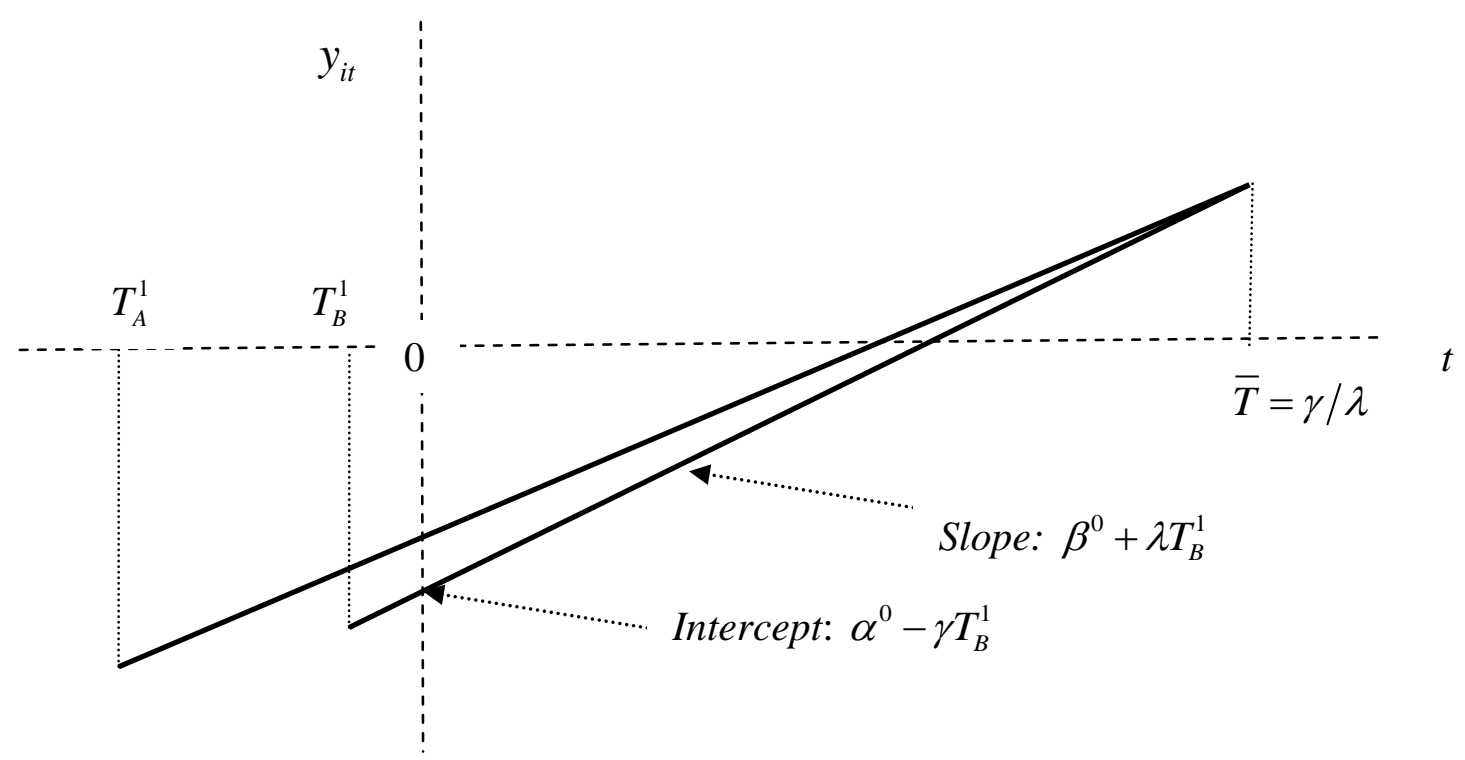




\section{Appendices}

\section{Appendix A-1: Joint significant test for model specification}

\begin{tabular}{|c|c|c|c|c|c|c|}
\hline \multicolumn{7}{|c|}{$\frac{\text { Standard F-test: }}{\text { Unrestricted Core Model }}$} \\
\hline \multicolumn{4}{|c|}{$\overline{\text { Fixed-effects (within) }}$ regression } & \multicolumn{3}{|c|}{ Number of obs = } \\
\hline \multicolumn{4}{|c|}{ Group variable: country_code } & Numbe: & f groups & 30 \\
\hline \multirow[t]{4}{*}{ R-sq: within } & $=0.9602$ & & & Obs pe & group: $\min =$ & \\
\hline & $=0.0860$ & & & & $\operatorname{avg}=$ & 14.9 \\
\hline & $=0.4596$ & & & & $\max =$ & 16 \\
\hline & & & & \multicolumn{3}{|c|}{$F(26,29) \quad=$} \\
\hline \multicolumn{4}{|c|}{$\operatorname{corr}\left(u_{-} i, x b\right)=-0.5203$} & \multicolumn{3}{|c|}{ (Std. Err. adjusted for 30 clusters in country_code) } \\
\hline \multirow[b]{2}{*}{ y 1} & \multicolumn{3}{|c|}{ Robust } & & \multirow[b]{2}{*}{ [95\% Conf. } & \multirow[b]{2}{*}{ Interval] } \\
\hline & Coef. & Std. Err. & t & $P>|t|$ & & \\
\hline dumNF2 । & .5877596 & .264706 & 2.22 & 0.034 & .0463751 & 1.129144 \\
\hline dumNF3 | & .8398694 & .3717518 & 2.26 & 0 & .0795517 & 1.600187 \\
\hline dumNF 4 | & .3729696 & .5130853 & 0.73 & 0.473 & -.6764077 & 1.422347 \\
\hline dumNF5 | & .64086 & .9499922 & 0.67 & 0.505 & -1.302092 & 2.583812 \\
\hline dumNF67 | & .0719463 & .5514667 & 0.13 & 0.897 & -1.05593 & 1.199822 \\
\hline Prv I & -.1199714 & .2206684 & -0.54 & 0.591 & -.5712889 & .331346 \\
\hline IndReg | & -.1798928 & .2987383 & -0.60 & 0 . & -.7908812 & .4310956 \\
\hline InGDPpc | & 1.032202 & 1.094641 & 0.94 & 0.353 & -1.206591 & 3.270994 \\
\hline lnUbpr | & -6.644412 & 3.83608 & -1.73 & 0.094 & -14.49008 & 1.201251 \\
\hline dumDG_only | & -.1747344 & .3225805 & -0.54 & 0.592 & -.8344856 & .4850168 \\
\hline dūmMix | & -1.190251 & .2336362 & -5.09 & 0.000 & -1.668091 & -.7124115 \\
\hline HHI_tech I & -2.710813 & .5387103 & -5.03 & 0.000 & -3.8126 & -1.609027 \\
\hline dumNF2t | & -.0114068 & .055319 & -0.21 & 0.838 & -.1245469 & .1017333 \\
\hline dumNF3t | & -.036527 & .0628624 & -0.58 & 0.566 & -.1650951 & .0920411 \\
\hline dumNF4t | & .0034379 & .0702757 & 0.05 & 0.961 & -.1402921 & .1471678 \\
\hline dumNF5t | & .0238131 & .1111814 & 0.21 & 0.832 & -.2035785 & .2512047 \\
\hline dumNF67t | & .0266996 & .0869262 & 0.31 & 0.761 & -.1510844 & .2044836 \\
\hline Prvt | & .0283783 & .0380266 & 0.75 & 0.462 & -.0493948 & .1061513 \\
\hline IndRegt | & .0359639 & .0332134 & 1.08 & 0.288 & -.0319651 & .1038928 \\
\hline InGDPpcT | & -.0409515 & .0416502 & -0.98 & 0.334 & -.1261357 & .0442328 \\
\hline InUbprT | & -.267178 & .0782624 & -3.41 & 0.002 & -.4272425 & -.1071135 \\
\hline dumDG_onlyt | & .1748323 & .0500392 & 3.49 & 0.002 & .0724906 & .277174 \\
\hline dumMixt | & .2722529 & .0465849 & 5.84 & 0.000 & .1769762 & .3675296 \\
\hline HHI_techT | & .4789624 & .0762145 & 6.28 & 0.000 & .3230863 & .6348386 \\
\hline$\overline{\mathrm{T}}$ _open | & .0779297 & .0869525 & 0.90 & 0.378 & -.099908 & .2557675 \\
\hline$t \quad 1$ & 1.491178 & .5118877 & 2.91 & 0.007 & .4442501 & 2.538106 \\
\hline T1t | & .0181631 & .0044301 & 4.10 & 0.000 & .0091026 & .0272237 \\
\hline _cons I & 15.49032 & 12.37903 & 1.25 & 0.221 & -9.82764 & 40.80827 \\
\hline sigma_u | & 2.288 & & & & & \\
\hline sigma_e | & .53968818 & & & & & \\
\hline$r \bar{h} \circ \mid$ & .94725 & & & to & $u_{-i}$ & \\
\hline
\end{tabular}

\section{Restricted Core Model}

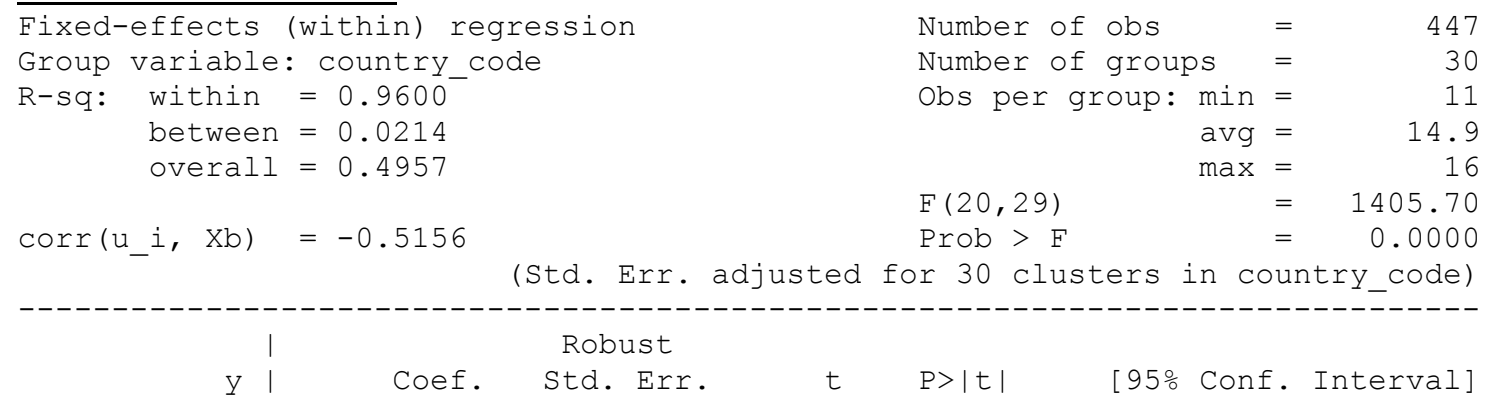




\begin{tabular}{|c|c|c|c|c|c|c|}
\hline N2 & .1188125 & .0572503 & 2.08 & 0.039 & .0062608 & .2313642 \\
\hline N3 & .1584818 & .0613633 & 2.58 & 0.010 & .0378441 & .2791195 \\
\hline N4 & .0124114 & .0573207 & 0.22 & 0.829 & -.1002787 & .1251015 \\
\hline N5 & .2614288 & .0659349 & 3.96 & 0.000 & .1318035 & .391054 \\
\hline N67 & .0532701 & .0799346 & 0.67 & 0.506 & -.1038778 & .2104181 \\
\hline PrvT & .0879723 & .0246857 & 3.56 & 0.000 & .0394412 & .1365034 \\
\hline IndRegT & .0297142 & .0172647 & 1.72 & 0.086 & -.0042275 & .0636558 \\
\hline InGDPpc & .8919164 & .4866697 & 1.83 & 0.068 & -.0648555 & 1.848688 \\
\hline InUbpr & -6.92371 & 1.671787 & -4.14 & 0.000 & -10.21037 & -3.637048 \\
\hline dumDG_only & .0417983 & .2532785 & 0.17 & 0.869 & -.4561364 & .539733 \\
\hline dümMix & -.7504647 & .2498793 & -3.00 & 0.003 & -1.241717 & -.2592127 \\
\hline HHI_tech & -1.444709 & .5624752 & -2.57 & 0.011 & -2.550512 & -.338907 \\
\hline lnGDPpcT & -.0716285 & .0211011 & -3.39 & 0.001 & -.1131124 & -.0301445 \\
\hline InUbprT & -.2722554 & .0524541 & -5.19 & 0.000 & -.3753778 & -.1691329 \\
\hline dumDG_onlyt & .1908458 & .0489266 & 3.90 & 0.000 & .0946581 & .2870335 \\
\hline dumMixt & .2583299 & .0485575 & 5.32 & 0.000 & .1628679 & .3537919 \\
\hline HHI_techT & .3519269 & .0575996 & 6.11 & 0.000 & .2386885 & .4651653 \\
\hline $\bar{T}$ _open & .2844822 & .0692941 & 4.11 & 0.000 & .148253 & .4207114 \\
\hline$t$ & 1.761327 & .3017621 & 5.84 & 0.000 & 1.168076 & 2.354578 \\
\hline T1t & .012334 & .0024384 & 5.06 & 0.000 & .0075401 & .0171279 \\
\hline cons & 15.83565 & 7.394024 & 2.14 & 0.033 & 1.299317 & 30.37199 \\
\hline \multicolumn{7}{|c|}{-------------+------------- - - - - - - - - - - - - - - - - - - - - - - - - - - - - - - - - - - - - - - - - - - - - - - - } \\
\hline sigma_u & 2.1901887 & & & & & \\
\hline sigma_e & .53623788 & & & & & \\
\hline rho & .94344531 & (fract & vari & le & $\left.u \_i\right)$ & \\
\hline
\end{tabular}

$F-$ statistics $=\frac{\left(R_{u}-R_{r}\right) / r}{\left(1-R_{u}\right) /\left(N-k_{u}-1\right)}=\frac{(0.9602-0.9600) / 7}{(1-0.9602) /(447-(27+29)-1)}=0.28$

Joint significance test: F-statistics $=0.28<\mathrm{F}(7,390)=2.01$; hence, we cannot reject the restricted model, so the restricted model specification is preferred. 


\section{Appendix A-2: Sensitivity check for threshold of mobile penetration}

Dependent variable: $y_{i t}=\ln \left(\right.$ MobPen $_{i t} /\left(100-\right.$ MobPen $\left.\left._{i t}\right)\right)$

\begin{tabular}{|c|c|c|c|c|}
\hline & \multicolumn{2}{|c|}{ w. China } & \multicolumn{2}{|c|}{ w.o. China } \\
\hline & Ceiling at 100 & "Ceiling capped at 99 & Ceiling at 100 & Ceiling capped at 99 \\
\hline \multicolumn{5}{|c|}{ Market structure: } \\
\hline \multirow[t]{2}{*}{$\mathrm{N}=2$} & $0.119 * *$ & $0.154 * * *$ & $0.113 * *$ & $0.150 * * *$ \\
\hline & 2.08 & 2.47 & 1.89 & 2.35 \\
\hline \multirow[t]{2}{*}{$\mathrm{N}=3$} & $0.158 * * *$ & $0.182 * * *$ & $0.148 * * *$ & $0.175^{* * *}$ \\
\hline & 2.58 & 2.77 & 2.34 & 2.62 \\
\hline \multirow[t]{2}{*}{$\mathrm{N}=4$} & 0.012 & 0.078 & -0.004 & 0.060 \\
\hline & 0.22 & 1.23 & -0.06 & 0.91 \\
\hline \multirow[t]{2}{*}{$\mathrm{N}=5$} & $0.261 * * *$ & $0.237 * * *$ & $0.258 * * *$ & $0.235 * * *$ \\
\hline & 3.96 & 3.31 & 3.86 & 3.24 \\
\hline \multirow[t]{2}{*}{$\mathrm{N}=6 \& 7$} & 0.053 & 0.029 & 0.048 & 0.021 \\
\hline & 0.67 & 0.32 & 0.59 & 0.23 \\
\hline \multicolumn{5}{|l|}{ Ownership: } \\
\hline \multirow[t]{2}{*}{ PrvT } & $0.088 * * *$ & $0.088 * * *$ & $0.078 * * *$ & $0.077 * * *$ \\
\hline & 3.56 & 3.28 & 3.04 & 2.81 \\
\hline \multicolumn{5}{|c|}{ Independent regulator: } \\
\hline \multirow[t]{2}{*}{ IndRegT } & $0.030 * *$ & $0.028 *$ & $0.029 *$ & $0.027 *$ \\
\hline & 1.72 & 1.46 & 1.60 & 1.38 \\
\hline \multicolumn{5}{|l|}{ Other: } \\
\hline \multirow[t]{2}{*}{$\operatorname{lnGDPpc}$} & $0.892 * *$ & $1.056 * *$ & 0.496 & 0.525 \\
\hline & 1.83 & 2.05 & 0.88 & 0.85 \\
\hline \multirow[t]{2}{*}{$\operatorname{lnGDPpcT}$} & $-0.072 * * *$ & $-0.034 *$ & $-0.059 * * *$ & -0.019 \\
\hline & -3.39 & -1.60 & -2.62 & -0.88 \\
\hline \multirow{2}{*}{$\operatorname{lnUbpr}$} & $-6.924 * * *$ & $-6.849 * * *$ & $-8.510 * * *$ & $-8.805 * * *$ \\
\hline & -4.14 & -3.70 & -3.83 & -3.70 \\
\hline \multirow[t]{2}{*}{$\operatorname{lnUbprT}$} & $-0.272 * * *$ & $-0.271 * * *$ & $-0.261 * * *$ & $-0.259 * * *$ \\
\hline & -5.19 & -4.74 & -4.88 & -4.45 \\
\hline \multirow[t]{2}{*}{ dumDG_only } & 0.042 & $-0.645^{* *}$ & 0.059 & $-0.621 * *$ \\
\hline & 0.17 & -2.25 & 0.23 & -2.12 \\
\hline \multirow[t]{2}{*}{ dumDG_onlyt } & $0.191 * * *$ & $0.255^{* * *}$ & $0.201 * * *$ & $0.265^{* * *}$ \\
\hline & 3.90 & 4.52 & 4.02 & 4.61 \\
\hline \multirow[t]{2}{*}{ dumMix } & $-0.750 * * *$ & $-0.876 * * *$ & $-0.765 * * *$ & $-0.872 * * *$ \\
\hline & -3.00 & -3.04 & -2.97 & -2.94 \\
\hline \multirow[t]{2}{*}{ dumMixt } & $0.258 * * *$ & $0.261 * * *$ & $0.270 * * *$ & $0.270 * * *$ \\
\hline & 5.32 & 4.66 & 5.42 & 4.72 \\
\hline \multirow[t]{2}{*}{ HHI_tech } & $-1.445^{* * *}$ & $-1.823 * * *$ & $-1.498 * * *$ & $-1.812 * * *$ \\
\hline & -2.57 & -2.82 & -2.58 & -2.72 \\
\hline HHI_techT & $0.352 * * *$ & $0.381 * * *$ & $0.363 * * *$ & $0.383 * * *$ \\
\hline & 6.11 & 5.95 & 6.12 & 5.83 \\
\hline Timeopen & $0.284 * * *$ & $0.336^{* * *}$ & $0.262 * * *$ & $0.314 * * *$ \\
\hline & 4.11 & 4.40 & 3.69 & 4.04 \\
\hline Time & $1.761 * * *$ & $1.311 * * *$ & $1.605 * * *$ & $1.144 * * *$ \\
\hline & 5.84 & 4.26 & 5.04 & 3.58 \\
\hline $\mathrm{T} 1 * \mathrm{t}$ & $0.012 * * *$ & $0.011 * * *$ & $0.013 * * *$ & $0.012 * * *$ \\
\hline & 5.06 & 4.57 & 5.26 & 4.80 \\
\hline & $\mathrm{n}=447$ & $\mathrm{n}=477$ & $\mathrm{n}=431$ & $\mathrm{n}=461$ \\
\hline & $\begin{array}{l}\text { R-sq = } 0.9600 \\
\text { (within) }\end{array}$ & $\mathrm{R}-\mathrm{sq}=0.9544$ (within) & $\begin{array}{l}\text { R-sq =0.9588 } \\
\text { (within) }\end{array}$ & $\mathrm{R}-\mathrm{sq}=0.9536$ (within) \\
\hline $\begin{array}{l}\text { Estimation } \\
\text { Procedure }\end{array}$ & $\mathrm{FE}$ & FE & FE & $\mathrm{FE}$ \\
\hline
\end{tabular}

Note: In all models, ***, **, and * indicate significant levels at 1\%,5\%, and 10\%, respectively; $\mathrm{z}$-statistics are reported below each coefficient in italic type. 


\section{Appendix A-3: First-stage regression on mobile price}

\begin{tabular}{|c|c|c|c|c|c|c|}
\hline Fixed-effects & (within) rec & sion & & Numbe & f obs & 447 \\
\hline Group variable & : country_cc & & & Numbe: & f groups & 30 \\
\hline R-sq: within & $=0.5753$ & & & Obs p & group: $\min =$ & 11 \\
\hline between & $=0.3640$ & & & & $\operatorname{avg}=$ & 14.9 \\
\hline overall & $=0.3980$ & & & & $\max =$ & 16 \\
\hline & & & & $F(25$, & & 4023.98 \\
\hline $\operatorname{corr}\left(u_{-} i, \quad \mathrm{xb}\right)$ & $=-0.6243$ & & & Prob & & 0.0000 \\
\hline & & td. $\operatorname{Err}$ & & & $n \mathrm{c}$ & $r$ \\
\hline | & & Robust & & & & \\
\hline $\operatorname{lnMbp}$ & Coef. & Std. Err. & $t$ & $P>|t|$ & [95\% Conf. & Interval] \\
\hline $\mathrm{N} 2$ & -.0056735 & .0082302 & -0.69 & 0.496 & -.0225062 & .0111591 \\
\hline N3 । & .010804 & .0112942 & 0.96 & 0.347 & -.0122952 & .0339031 \\
\hline N4 । & -.0174117 & .0087417 & -1.99 & 0.056 & -.0352906 & .0004671 \\
\hline N5 । & .0050004 & .0080457 & 0.62 & 0.539 & -.011455 & .0214557 \\
\hline N67 । & -.0406738 & .0125674 & -3.24 & 0.003 & -.0663771 & -.0149706 \\
\hline PrvT | & .0251389 & .0094245 & 2.67 & 0.012 & .0058635 & .0444143 \\
\hline IndRegT | & -.0025693 & .0055263 & -0.46 & 0.645 & -.0138719 & .0087333 \\
\hline $\operatorname{lnGDPpC}$ & .1384868 & .1276527 & 1.08 & 0.287 & -.1225922 & .3995659 \\
\hline InGDPpcT | & -.0228119 & .0091612 & -2.49 & 0.019 & -.0415487 & -.0040751 \\
\hline InUtopr | & .8505257 & .3921072 & 2.17 & 0.038 & .0485765 & 1.652475 \\
\hline InUbprT | & .0343904 & .0168947 & 2.04 & 0.051 & -.0001631 & .0689439 \\
\hline dumDG_only | & .0122187 & .1038358 & 0.12 & 0.907 & -.2001492 & .2245867 \\
\hline dumDG_onlyt | & .0047326 & .0128395 & 0.37 & 0.715 & -.0215271 & .0309922 \\
\hline$\overline{\mathrm{d} u m M i x}$ | & .1542199 & .0787601 & 1.96 & 0.060 & -.0068625 & .3153023 \\
\hline dumMixt | & -.0118121 & .0119102 & -0.99 & 0.330 & -.0361713 & .012547 \\
\hline HHI_tech I & .3129437 & .167572 & 1.87 & 0.072 & -.0297795 & .6556669 \\
\hline HHI_techT | & -.0374128 & .0157454 & -2.38 & 0.024 & -.0696158 & -.0052099 \\
\hline $\ln \operatorname{Fxp}$ & .3372876 & .4574617 & 0.74 & 0.467 & -.5983267 & 1.272902 \\
\hline $\ln \mathrm{Fxp}$ & .0348638 & .0377597 & 0.92 & 0.363 & -.0423635 & .1120911 \\
\hline T_open | & .0189819 & .0177532 & 1.07 & 0.294 & -.0173275 & .0552914 \\
\hline$t \quad 1$ & .0873642 & .0893835 & 0.98 & 0.336 & -.0954456 & .2701741 \\
\hline T1t | & -.0014651 & .0009917 & -1.48 & 0.150 & -.0034934 & .0005631 \\
\hline $\operatorname{lnL} 1 \mathrm{Mbp}$ & .5331912 & .0629351 & 8.47 & 0.000 & .4044745 & .6619079 \\
\hline $\operatorname{lnMblp} \mid$ & -.0500631 & .0165505 & -3.02 & 0.003 & -.0826019 & -.0175243 \\
\hline InPop | & .1353649 & .4630391 & 0.29 & 0.772 & -.8116564 & 1.082386 \\
\hline _cons I & -7.16723 & 7.324932 & -0.98 & 0.336 & -22.1484 & 7.813938 \\
\hline sigma_u | & .26261451 & & & & & \\
\hline sigma_e | & .14193033 & & & & & \\
\hline$r \bar{h} \circ$ । & .7739414 & $\operatorname{lfr}$ & $\mathrm{va}$ & e due & $u_{-}$i) & \\
\hline
\end{tabular}

\section{Excluding China}

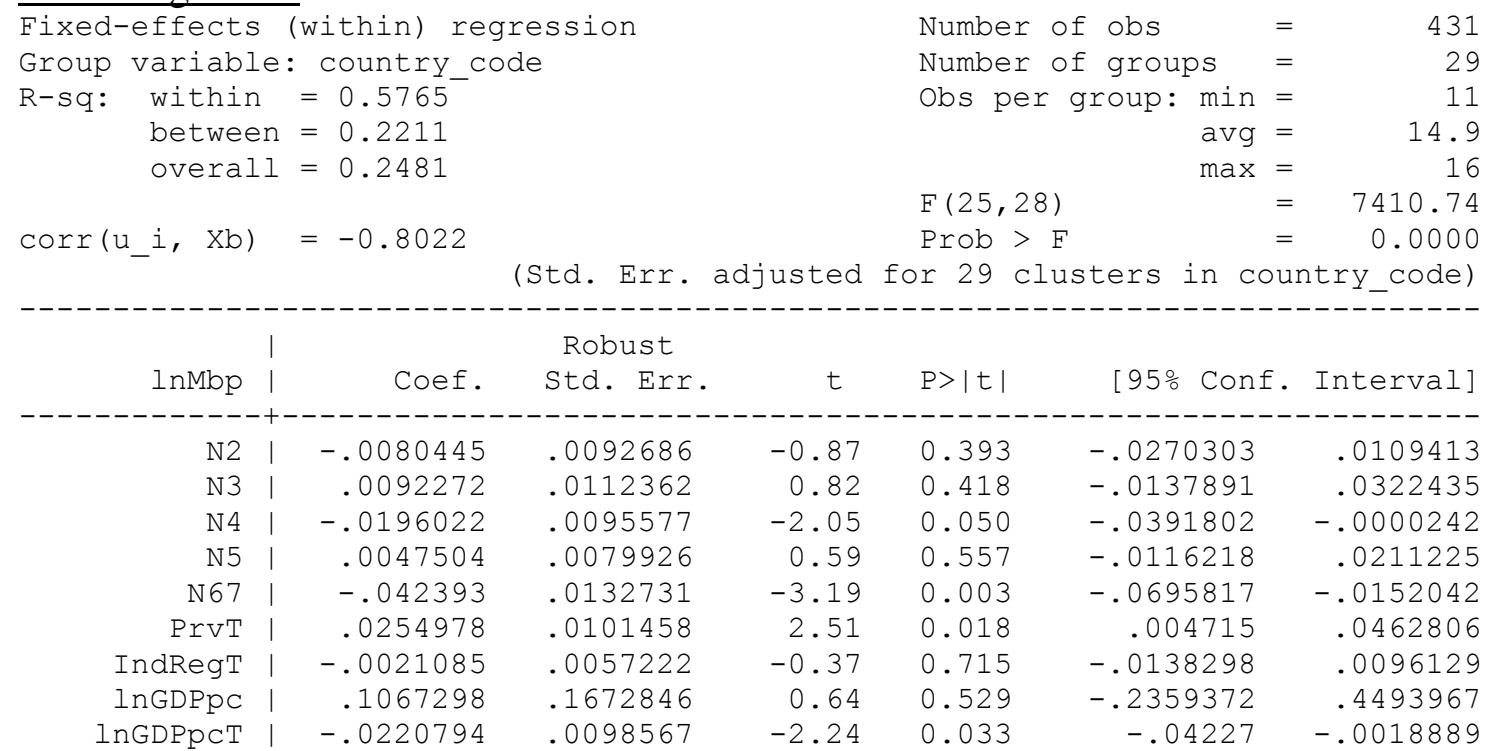




\begin{tabular}{|c|c|c|c|c|c|c|}
\hline InUbpr & .585158 & .6641794 & 0.88 & 0.386 & -.7753518 & 1.945668 \\
\hline InUbprt & .0338654 & .0175265 & 1.93 & 0.064 & -.0020361 & .0697668 \\
\hline dumDG_only & .0186223 & .1065345 & 0.17 & 0.862 & -.1996038 & .2368484 \\
\hline dumDG_onlyt & .0035631 & .0128714 & 0.28 & 0.784 & -.0228028 & 02992 \\
\hline$\overline{\mathrm{d}} u \mathrm{mMix}$ & .1646612 & .0819939 & 2.01 & 0.054 & -.0032957 & .332618 \\
\hline dumMixt & -.0130362 & .0121952 & -1.07 & 0.294 & -.0380168 & .0119445 \\
\hline HHI_tech & .3326432 & .1753011 & 1.90 & 0.068 & -.0264449 & .691731 \\
\hline HHI_techT & -.0386068 & .0167753 & $-2 \cdot 30$ & 0.029 & -.0729694 & -.004244 \\
\hline $\ln F x p$ & .3371562 & .4681648 & 0.72 & 0.477 & -.6218359 & 1.29614 \\
\hline InFxpT & .0376035 & .0376794 & 1.00 & 0.327 & -.0395793 & .114786 \\
\hline $\mathrm{T}_{\text {_open }}$ & .017184 & .0178626 & 0.96 & 0.344 & -.0194059 & .053773 \\
\hline t & .086357 & .0984518 & 0.88 & 0.388 & -.1153123 & .288026 \\
\hline T1t & -.001397 & .0010328 & -1.35 & 0.187 & -.0035126 & .000718 \\
\hline $\operatorname{lnL} 1 \mathrm{Mbp}$ & .5306575 & .0628891 & 8.44 & 0.000 & .4018349 & .659480 \\
\hline $\operatorname{lnMblp}$ & -.0485556 & .0170205 & -2.85 & 0.005 & -.0820226 & -.015088 \\
\hline $\ln P o p$ & .2467225 & .5717449 & 0.43 & 0.669 & -.9244439 & 1.4178 \\
\hline _cons & -7.584087 & 7.681014 & -0.99 & 0.332 & -23.31793 & 8.14975 \\
\hline sigma_u & .3740908 & & & & & \\
\hline sigma_e & .1444736 & & & & & \\
\hline$r \bar{h} \circ$ & .8702085 & (fraction & V & טיוית 0 & $u_{-}$i) & \\
\hline
\end{tabular}




\section{Appendix A-4: Hausman Test for Endogeneity of Number of Firms}

- xtivreg y (InNF InNFT = Prv IndReg itcIndPrv PrvT IndRegT InGDPpc lnGDPpcT lnUbpr lnUbprT dumDG only dumMix dumDG_onlyt dumMixt HHI_tech HHI_techT T_open $t$ T1t lnPop lnMblp) PrvT IndRegt lnGDPpc InG̈DPpct lnUbpr lnUbp̄rT dumDG_only dumDG_onlyt dumMix dumMixt HHI_tech HHI_techT T_open $t$ Tlt, fe Fixed-effects (within) IV regression Group variable: country_code

R-sq: within $=0.9159$ between $=0.0123$ overall $=0.4138$ $\operatorname{corr}\left(u_{-} i, \mathrm{Xb}\right)=-0.5969$ Number of obs $\quad=\quad 447$ Number of groups $\quad 30$ Obs per group: $\min =\quad 11$ 11
4.9 $\operatorname{avg}=$ 16

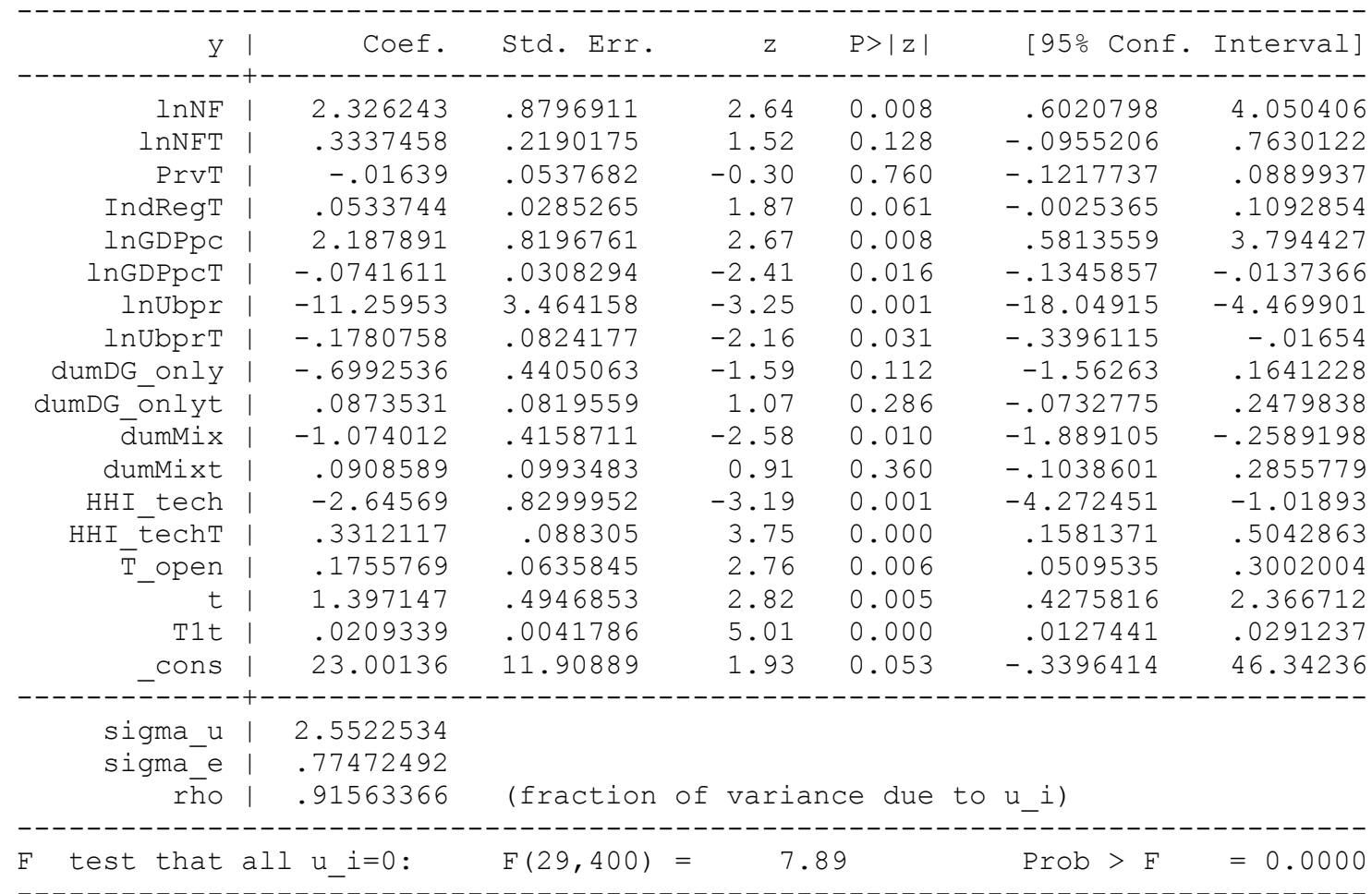

Instrumented: lnNF lnNFT

Instruments: $\quad$ PrvT IndRegT lnGDPpc InGDPpcT lnUbpr lnUbprT dumDG_only dumDG_onlyt

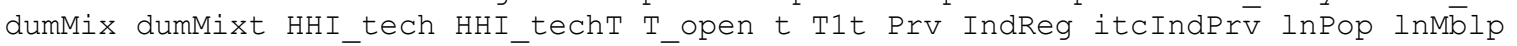

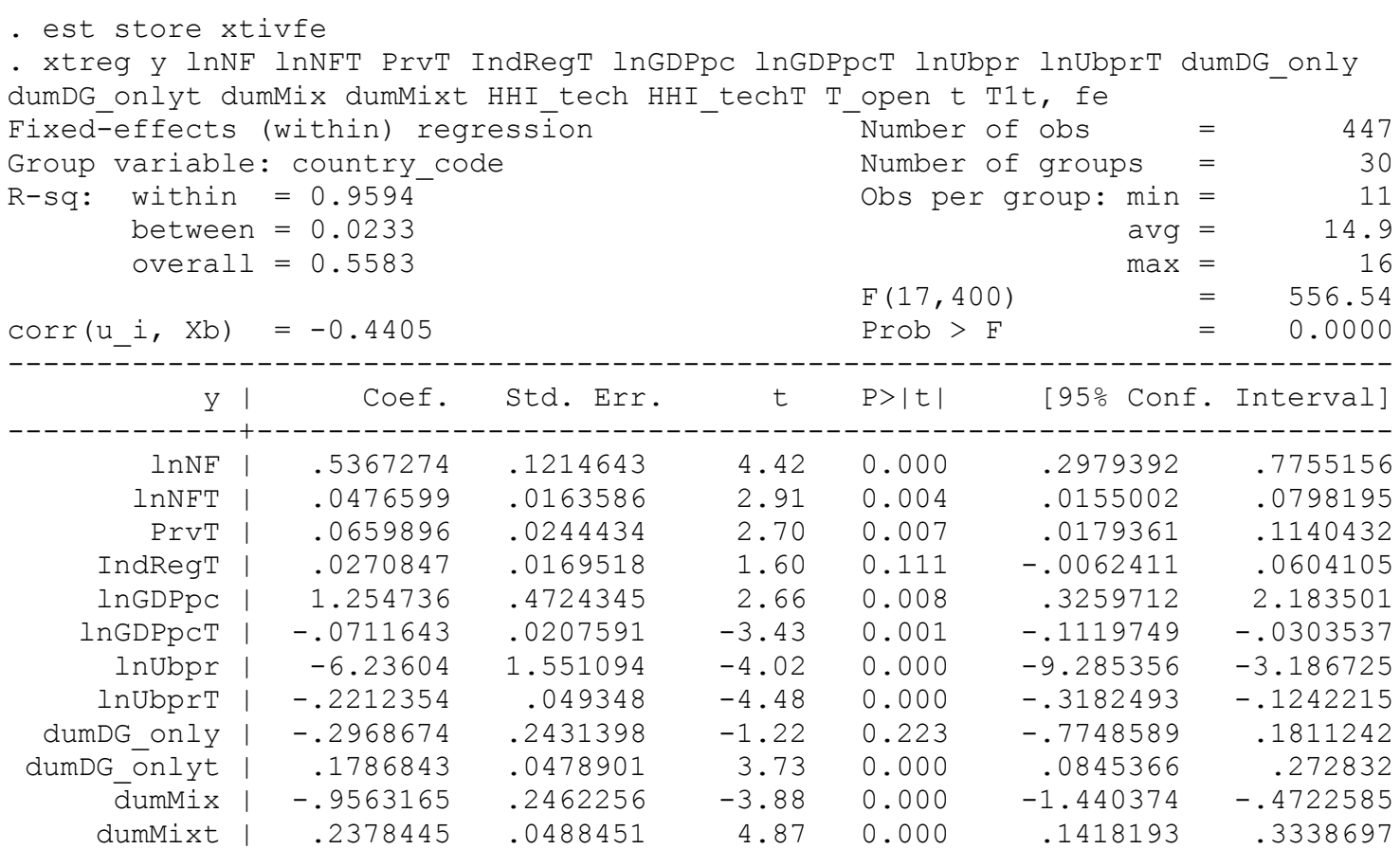




\begin{tabular}{|c|c|c|c|c|c|c|}
\hline HHI_tech I & -2.081755 & .5452815 & -3.82 & 0.000 & -3.153731 & -1.00978 \\
\hline HHI ' techT । & .4234521 & .0519338 & 8.15 & 0.000 & .3213549 & .5255493 \\
\hline$\overline{\mathrm{T}}$ _open | & .1718507 & .0398425 & 4.31 & 0.000 & .0935238 & .2501777 \\
\hline t 1 & 1.572267 & .2724909 & 5.77 & 0.000 & 1.036574 & 2.10796 \\
\hline T1t | & .016075 & .002347 & 6.85 & 0.000 & .011461 & .0206891 \\
\hline _cons | & 10.52682 & 6.722302 & 1.57 & 0.118 & -2.688636 & 23.74228 \\
\hline \begin{tabular}{r|r} 
sigma_u & \\
sigma_e & \\
rh̆o &
\end{tabular} & $\begin{array}{r}1.9513805 \\
.53819764 \\
.92930965\end{array}$ & (fraction & of var & e du & u i) & \\
\hline $\begin{array}{l}\text { test that all } \\
\text { est store xtf } \\
\text { hausman xtivf }\end{array}$ & $u_{-} i=0$ : & $F(29,400)$ & 17 & & Prob & $=0.0$ \\
\hline
\end{tabular}

hausman xtivfe xtfe

\begin{tabular}{|c|c|c|c|c|c|}
\hline & i & $\begin{array}{c}\text { (b) } \\
\text { xtivfe }\end{array}$ & $\begin{array}{l}\text { (B) } \\
x t f e\end{array}$ & $\begin{array}{c}(\mathrm{b}-\mathrm{B}) \\
\text { Difference }\end{array}$ & $\begin{array}{c}\operatorname{sqrt}\left(\text { diag }\left(V \_b-V \_B\right)\right) \\
\text { S.E. }\end{array}$ \\
\hline $\operatorname{lnNF}$ & | & 2.326243 & .5367274 & 1.789515 & .8712651 \\
\hline lnNET & | & .3337458 & .0476599 & .2860859 & .2184057 \\
\hline PrvT & | & -.01639 & .0659896 & -.0823797 & .0478909 \\
\hline IndRegT & | & .0533744 & .0270847 & .0262897 & .0229434 \\
\hline InGDPpc & | & 2.187891 & 1.254736 & .9331554 & .6698317 \\
\hline $\operatorname{lngDPpcT}$ & | & -.0741611 & -.0711643 & -.0029968 & .0227928 \\
\hline InUbpr & | & -11.25953 & -6.23604 & -5.023487 & 3.097499 \\
\hline InUbprT & i & -.1780758 & -.2212354 & .0431596 & .066011 \\
\hline dumDG_only & | & -.6992536 & -.2968674 & -.4023863 & .3673266 \\
\hline dumDG_onlyt & | & .0873531 & .1786843 & -.0913312 & .066508 \\
\hline dumMix & | & -1.074012 & -.9563165 & -.1176958 & .3351444 \\
\hline dumMixt & | & .0908589 & .2378445 & -.1469856 & .0865114 \\
\hline HHI_tech & | & -2.64569 & -2.081755 & -.5639348 & .6257476 \\
\hline HHI_techT & | & .3312117 & .4234521 & -.0922404 & .0714189 \\
\hline$\overline{\mathrm{T}}$ open & | & .1755769 & .1718507 & .0037262 & .0495537 \\
\hline t & | & 1.397147 & 1.572267 & -.1751199 & .4128708 \\
\hline $\mathrm{T} 1 \mathrm{t}$ & | & .0209339 & .016075 & .0048589 & .0034571 \\
\hline
\end{tabular}

$\mathrm{b}=$ consistent under $\mathrm{HO}$ and $\mathrm{Ha}$; obtained from xtivreg $\mathrm{B}=$ inconsistent under Ha, efficient under Ho; obtained from xtreg Test: Ho: difference in coefficients not systematic

$$
\begin{aligned}
\operatorname{chi2}(17) & = & (b-B) \cdot\left[\left(V_{-} b_{-}-V_{-} B\right)^{\wedge}(-1)\right](b-B) \\
& = & 4.31 \\
\text { Probschi2 } & = & 0.9992
\end{aligned}
$$

\section{Excluding China}

. xtivreg y (InNF InNFT = Prv IndReg itcIndPrv PrvT IndRegT InGDPpc lnGDPpcT InUbpr InUbprT dumDG only dumMix dumDG onlyt dumMixt HHI tech HHI techT $T$ open $t$ T1t lnPop

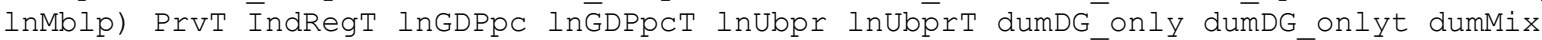
dumMixt HHI_tech HHI_techT T_open $t$ Tlt if country_code $>1$, fe

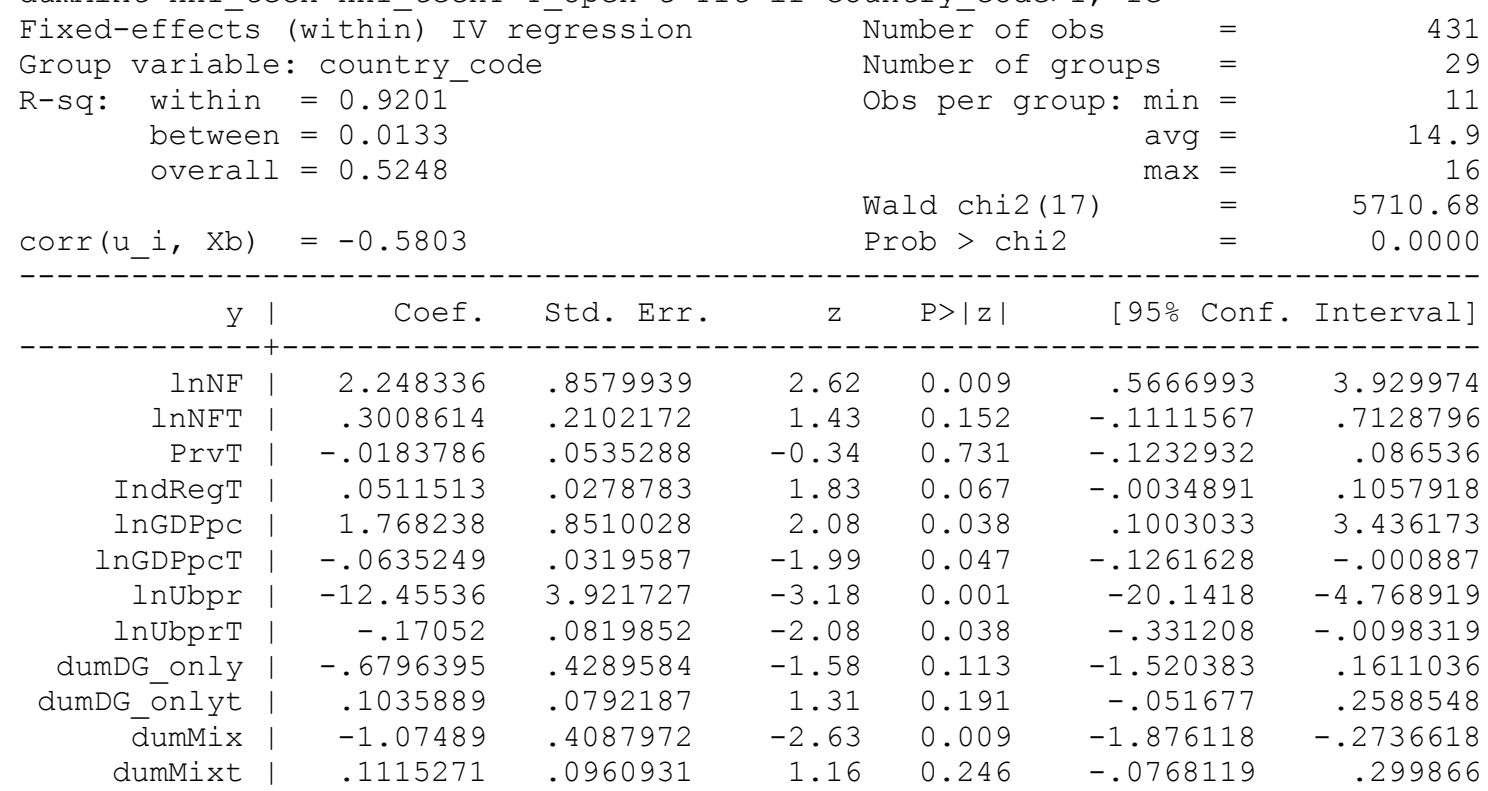




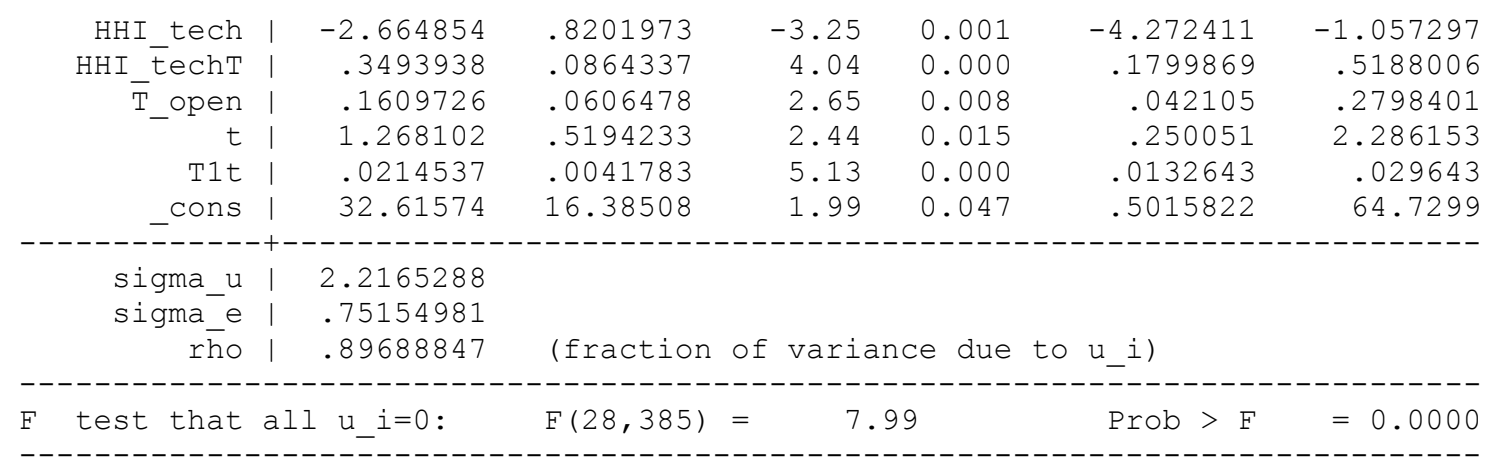

Instrumented: $\quad$ lnNF lnNFT

Instruments: $\quad$ PrvT IndRegT lnGDPpc lnGDPpcT lnUbpr lnUbprT dumDG_only dumDG_onlyt dumMix dumMixt HHI_tech HHI_techT T_open t Tlt Prv IndReg itcIndPrV lnPop lnMblp

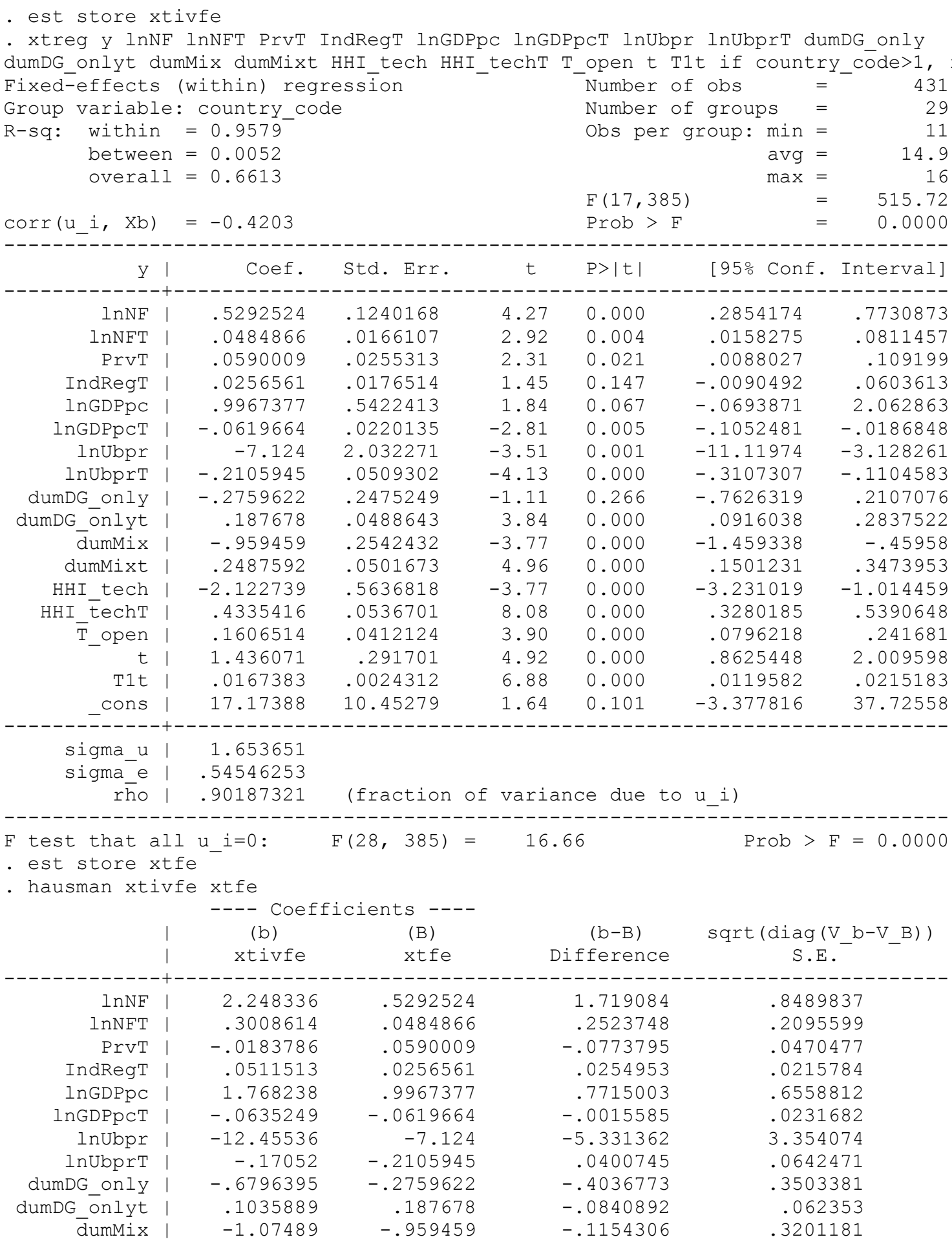




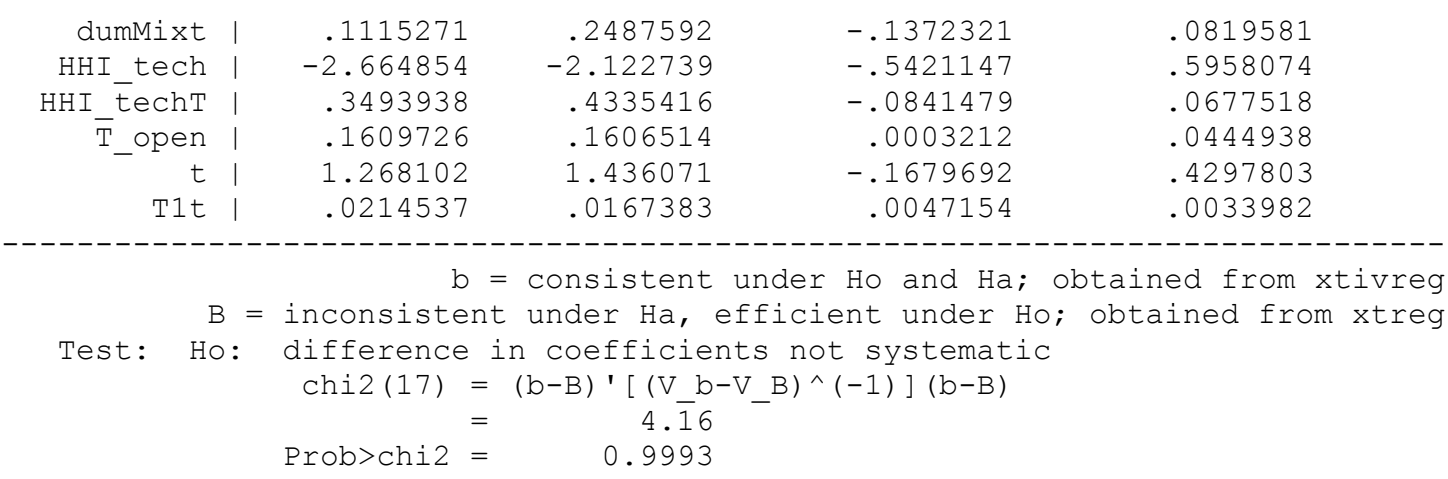

The Hausman test results suggest that we have no evidence in favour of instrumental estimation. 


\section{Appendix A-5: Hausman Test for Endogeneity of Mobile Price}

. xtivreg y (lnMbp lnMbpT $=\mathrm{N} 2 \mathrm{~N} 3 \mathrm{~N} 4 \mathrm{~N} 5 \mathrm{~N} 67$ PrvT IndRegT lngDPpc lngDPpcT lnUbpr InUbprT dumDG_only dumDG_onlyt dumMix dumMixt HHI_tech HHI_techT lnFxp lnFxpT lnL1Mbp lnMblp lnPop $\bar{T}$ open $t$ T1 $\bar{t})$ N2 N3 N4 N5 N67 PrvT IñdRegT lnḠDPpc lnGDPpct lnUbpr lnUbprT dumDG_only dumDG_onlyt dumMix dumMixt HHI_tech HHI_techT lnFxp lnFxpT T_open $t$ T1t, fe

Fixed-effects (within) IV regression Group variable: country_code

R-sq: within $=0.9608$ between $=0.0357$ overall $=0.6976$

$\operatorname{corr}\left(\mathrm{u}_{-} \mathrm{i}, \mathrm{Xb}\right)=-0.3506$ Number of obs $\quad=\quad 447$ Number of groups $\quad 30$ Obs per group: $\min =\quad 11$ 11
4.9 $\begin{array}{rr}\operatorname{avg}= & 14.9 \\ \max = & 16\end{array}$ Wald chi2(24) $=11389.77$ Prob $>$ chi2 $=0.0000$

\begin{tabular}{|c|c|c|c|c|c|c|c|}
\hline $\mathrm{y}$ & | & Coef. & Std. Err. & z & $\mathrm{P}>|\mathrm{z}|$ & [95\% Conf & Interval] \\
\hline $\operatorname{lnMbp}$ & | & -1.90784 & .4869264 & -3.92 & 0.000 & -2.862198 & -.9534814 \\
\hline lnMbpT & 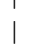 & .1324585 & .0435168 & 3.04 & 0.002 & .0471673 & .2177498 \\
\hline N2 & | & .0649829 & .0630896 & 1.03 & 0.303 & -.0586705 & .1886362 \\
\hline N3 & | & .1107162 & .0684565 & 1.62 & 0.106 & -.0234561 & .2448884 \\
\hline N4 & i & -.0326395 & .0643114 & -0.51 & 0.612 & -.1586875 & .0934085 \\
\hline N5 & | & .2129367 & .0729932 & 2.92 & 0.004 & .0698727 & .3560006 \\
\hline N67 & i & -.0675878 & .0876942 & -0.77 & 0.441 & -.2394653 & .1042897 \\
\hline PrvT & i & .1210588 & .0272499 & 4.44 & 0.000 & .06765 & .1744676 \\
\hline IndRegT & 1 & .0208066 & .0183806 & 1.13 & 0.258 & -.0152187 & .0568319 \\
\hline lnGDPpc & | & 1.759283 & .5632065 & 3.12 & 0.002 & .6554182 & 2.863147 \\
\hline InGDPpcT & | & -.111497 & .0254904 & -4.37 & 0.000 & -.1614573 & -.0615367 \\
\hline lnUbpr & 1 & -4.096746 & 1.906987 & -2.15 & 0.032 & -7.834371 & -.3591198 \\
\hline InUbprT & 1 & -.1906964 & .0585271 & -3.26 & 0.001 & -.3054074 & -.0759854 \\
\hline dumDG_only & i & -.1789307 & .2884868 & -0.62 & 0.535 & -.7443544 & .3864929 \\
\hline dumDG_onlyt & 1 & .2365798 & .0556751 & 4.25 & 0.000 & .1274586 & .3457009 \\
\hline $\bar{d} u m M i x$ & i & -.698015 & .2618654 & -2.67 & 0.008 & -1.211262 & -.1847682 \\
\hline dumMixt & I & .2722239 & .0523849 & 5.20 & 0.000 & .1695513 & .3748964 \\
\hline HHI_tech & 1 & -1.018925 & .5928121 & -1.72 & 0.086 & -2.180816 & .1429651 \\
\hline $\mathrm{HHI}_{-} \overline{\mathrm{techT}}$ & i & .2845033 & .0642676 & 4.43 & 0.000 & .1585411 & .4104655 \\
\hline $\ln \operatorname{Fxp}$ & 1 & 2.370112 & 1.949098 & 1.22 & 0.224 & -1.450049 & 6.190273 \\
\hline InFxpT & i & .1156328 & .1498442 & 0.77 & 0.440 & -.1780565 & .409322 \\
\hline T_open & 1 & .2887751 & .0749649 & 3.85 & 0.000 & .1418467 & .4357035 \\
\hline t & | & 1.675432 & .3384858 & 4.95 & 0.000 & 1.012012 & 2.338852 \\
\hline $\mathrm{T} 1 \mathrm{t}$ & I & .0096953 & .002651 & 3.66 & 0.000 & .0044994 & .0148912 \\
\hline _cons & I & -3.426989 & 9.423606 & -0.36 & 0.716 & -21.89692 & 15.04294 \\
\hline sigma_u & I & 1.5169 & & & & & \\
\hline sigma_e & I & .55499476 & & & & & \\
\hline$r \bar{h} \circ$ & 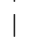 & .88195351 & 1 & var & ec & u_i) & \\
\hline test that & & $u_{-1}{ }^{\prime}$ & $F(29,393)$ & 12 & & Prob $>F$ & $=0.0$ \\
\hline
\end{tabular}

Instrumented: $\quad$ lnMbp lnMbpt

Instruments: N2 N3 N4 N5 N67 PrvT IndRegT lnGDPpc lngDPpct lnUbpr lnUbprT dumDG_only dumDG_onlyt dumMix dumMixt HHI_tech HHI_techT $\operatorname{lnFxp} l n F x p T$ t_open $t$ T1t $\operatorname{lnL} 1 \mathrm{Mb} \mathrm{p}$ lnMblp ln $\mathrm{n}$ op

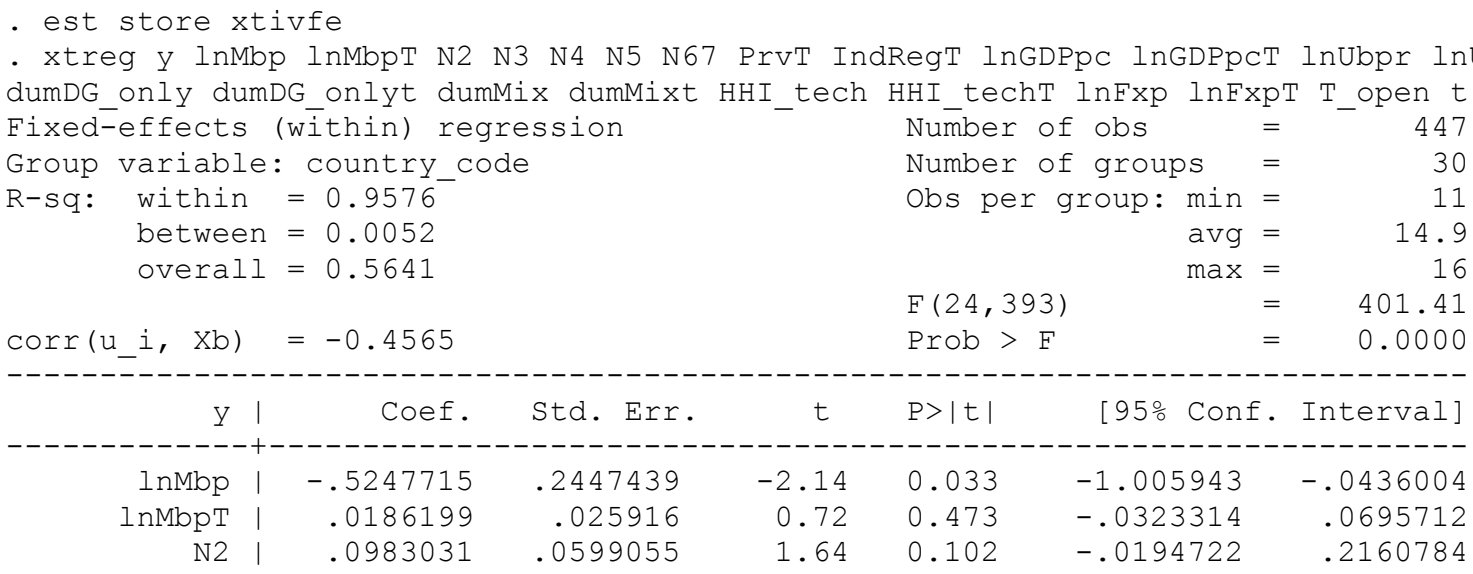




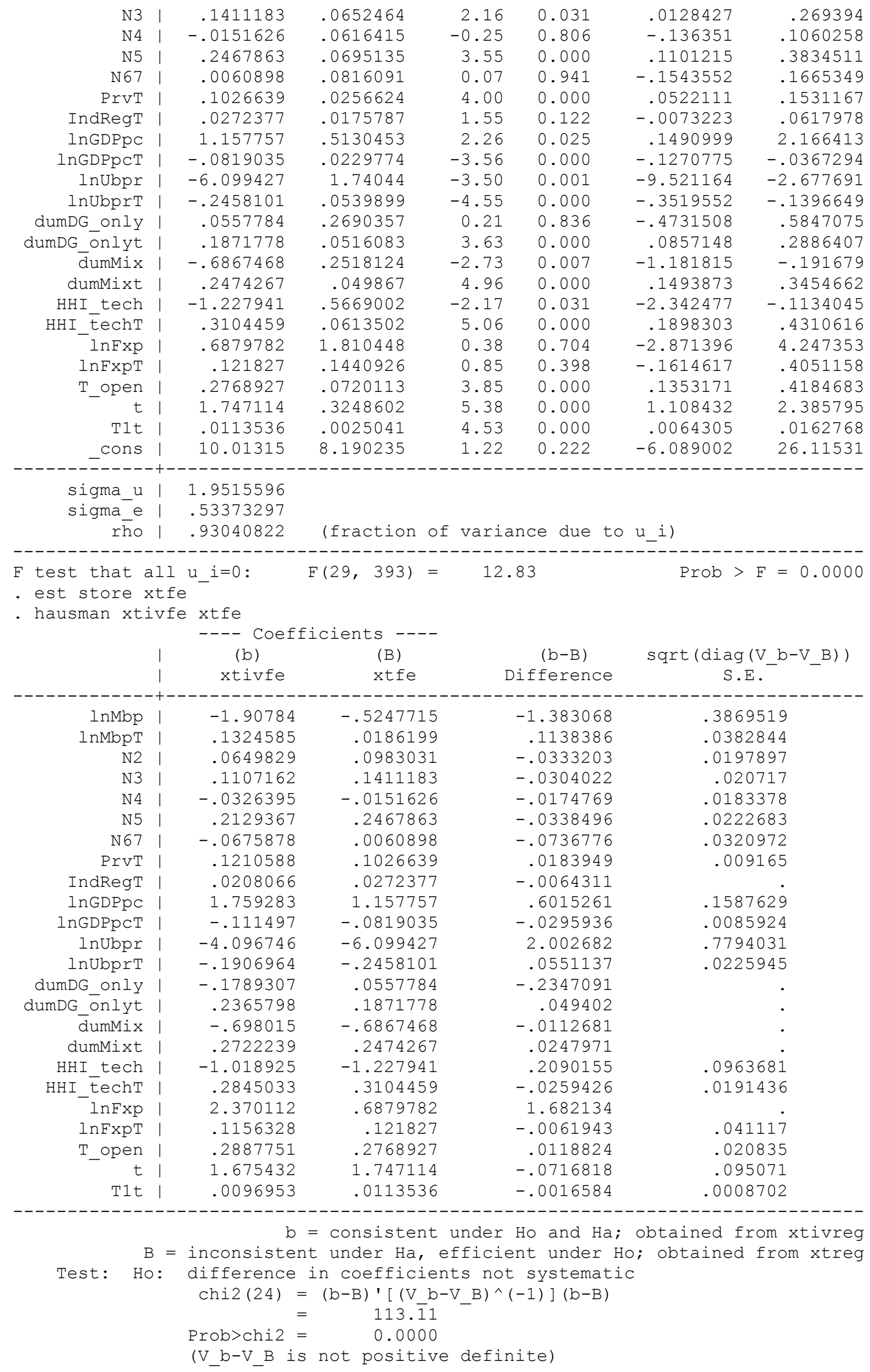




\section{Excluding China}

- xtivreg y (InMbp InMbpT = N2 N3 N4 N5 N67 PrvT IndRegT lngDPpc lnGDPpct lnUbpr InUbprT dumDG_only dumDG_onlyt dumMix dumMixt HHI_tech HHI_techT lnFxp lnFxpT lnL1Mbp lnMblp lnPop $\bar{T}$ open $t$ T1t) N2 N3 N4 N5 N67 PrvT IndRegT lnG̈DPpc lnGDPpct lnUbpr lnUbprT dumDG only dumDG onlyt dumMix dumMixt HHI tech HHI techT $\operatorname{lnFxp} \operatorname{lnFxpT} T$ open $t$ T1t if country_code>1, fe Fixed-effects (within) IV regression Group variable: country_code

R-sq: within $=0.9596$ between $=0.0516$ overall $=0.6989$

$$
\operatorname{corr}\left(u_{-} i, \mathrm{Xb}\right)=-0.4185
$$

$\begin{array}{rlr}\text { Number of obs } & = \\ \text { Number of groups } & = & 431 \\ \text { Obs per group: } \min & = & 29 \\ \text { avg } & = & 11 \\ \max & = & 14.9 \\ \text { Wald chi2(24) } & = & 10206.34 \\ \text { Prob chi2 } & = & 0.0000\end{array}$

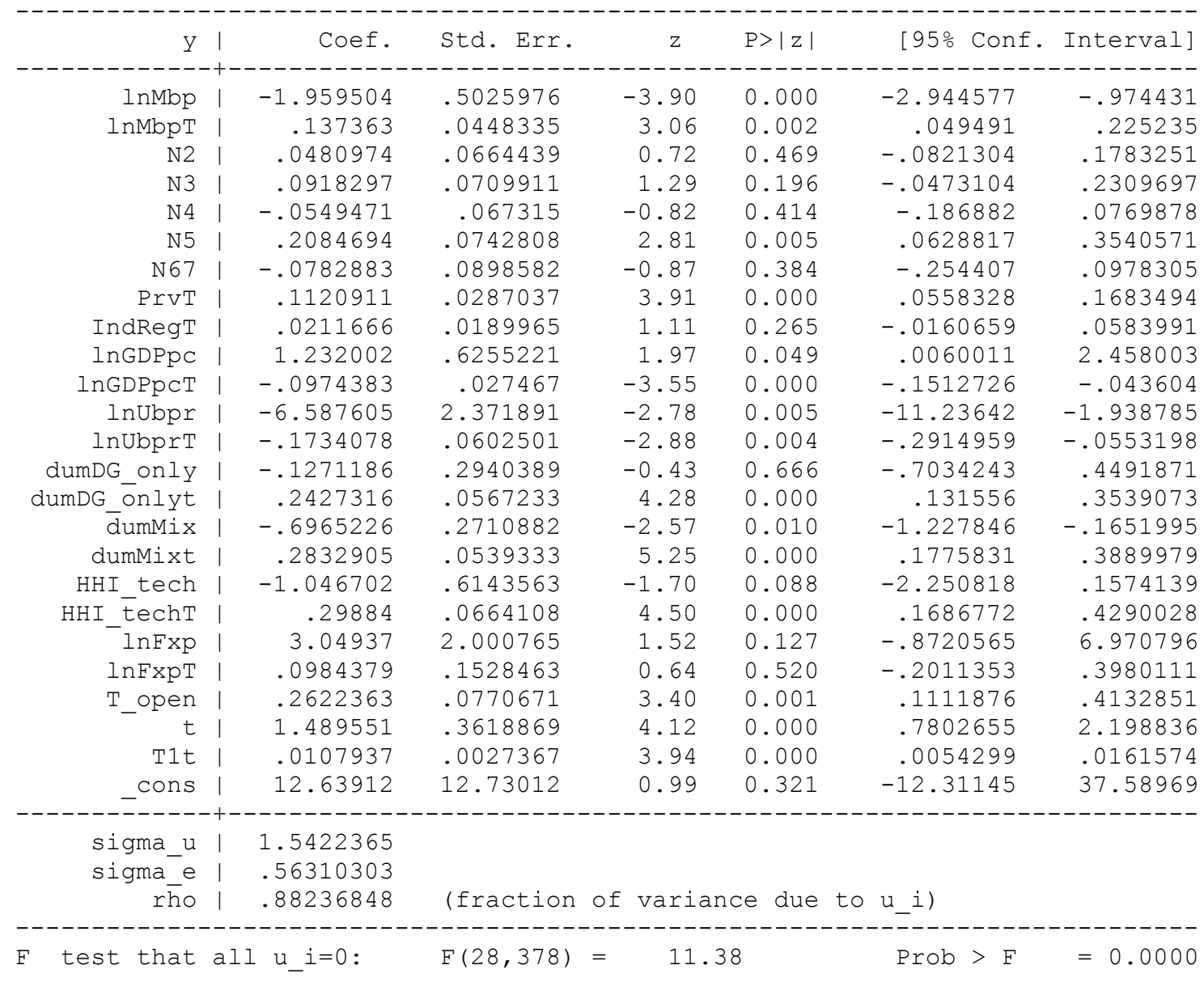

Instrumented: $\quad$ InMbp lnMbpT

Instruments: N2 N3 N4 N5 N67 PrvT IndRegT InGDPpc InGDPpcT InUbpr InUbprT dumDG_only dumDG_onlyt dumMix dumMixt HHI_tech HHI_techT lnFxp lnFxpT T_open t T1t lnL1M̄̄p lnMblp lñpop

- est store xtivfe

- xtreg y lnMbp lnMbpT N2 N3 N4 N5 N67 PrvT IndRegT lngDPpc lngDPpcT lnUbpr lnUbprT dumDG_only dumDG_onlyt dumMix dumMixt HHI_tech HHI_techT lnFxp lnFxpT T_open t T1t if country_code>1, fe

Fixed-effects (within) regression

Group variable: country_code

R-sq: within $=0.9560$

between $=0.0169$

overall $=0.6453$

$\operatorname{corr}\left(u_{-} i, \mathrm{Xb}\right)=-0.4624$

$\begin{array}{llr}\text { Number of obs } & = & 431 \\ \text { Number of groups } & = & 29 \\ \text { Obs per group: min } & = & 11 \\ \text { avg } & = & 14.9 \\ \mathrm{max} & = & 16 \\ \text { F }(24,378) & = & 373.77 \\ \text { Prob }>\text { F } & & 0.0000\end{array}$

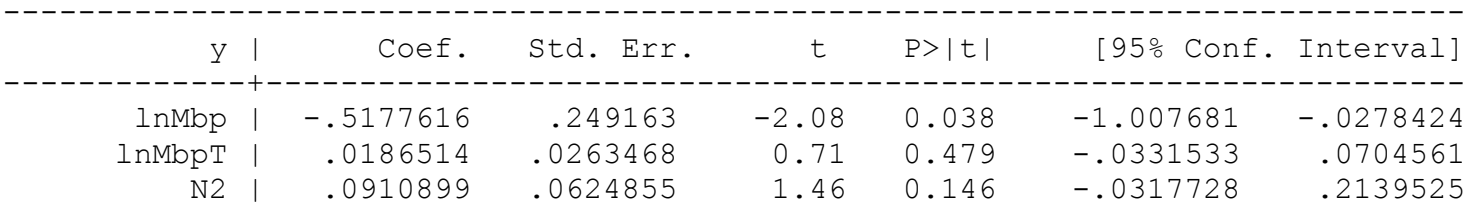




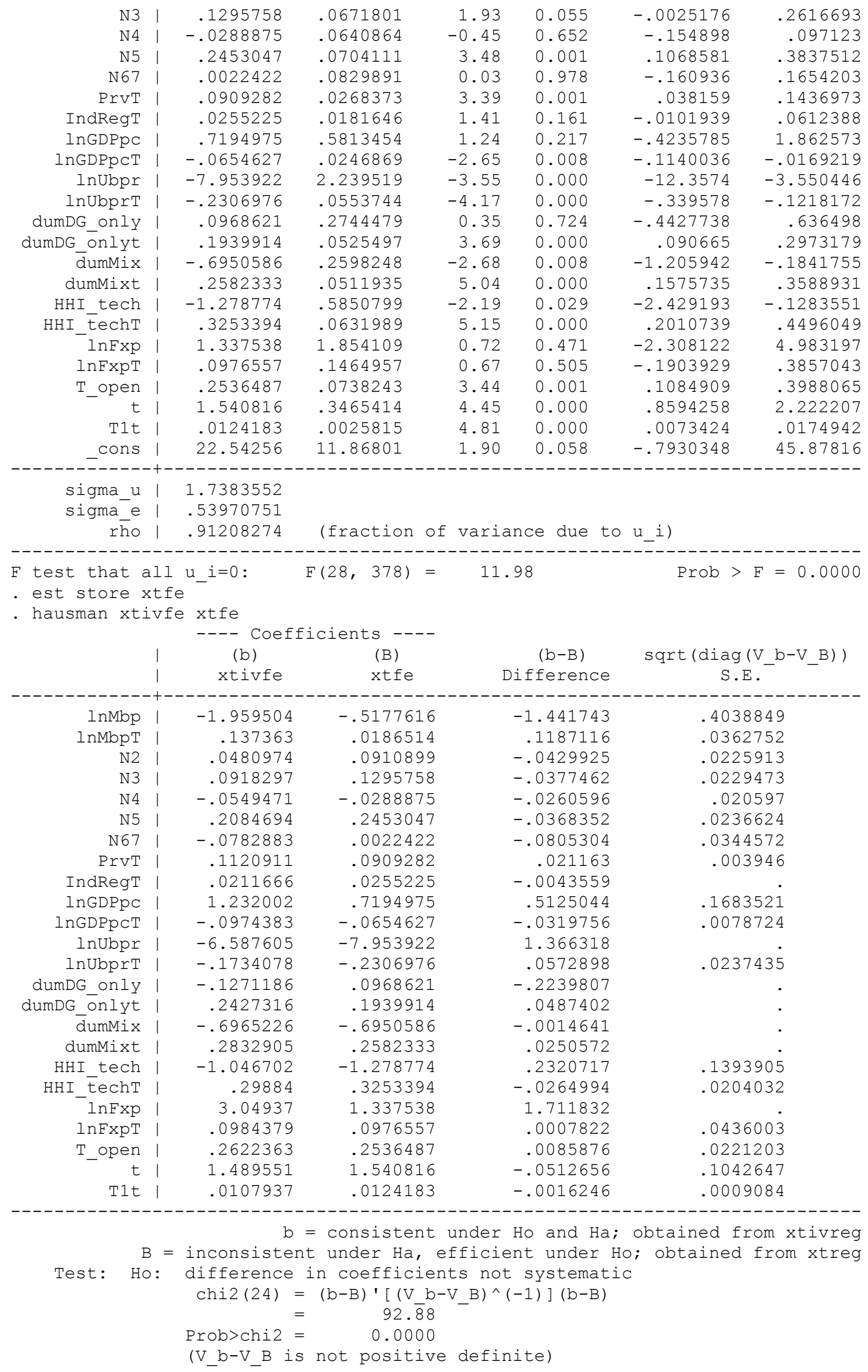

Hausman test results suggest that we have evidence that the instrumental model is preferred (i.e. mobile price is endogenous that requires instruments). 